\title{
Women's History Month
}

\section{Margaret A. Readdy and Christine Taylor, Guest Editors}

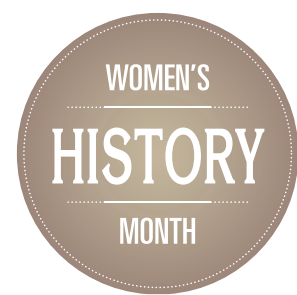

The history of women in mathematics in the US started more than 130 years ago. Winifred Edgerton Merrill ${ }^{1}$ became the first woman to receive $\mathrm{a} \mathrm{PhD}$ (1886) in mathematics in the US at Columbia. Christine Ladd had earned the degree from Johns Hopkins four years earlier, but it was not granted until 1926. The University of Chicago was a leading producer of PhDs for women in mathematics prior to World War II. These early doctorate recipients include Anna Pell Wheeler (1910), the first woman to deliver an invited address to the AMS (1923) and later chairwoman of Bryn Mawr's mathematics department; Pauline Sperry (1916), who spent most of her career at Berkeley; and Mayme Irwin Logsdon (1921), the only woman to hold a regular faculty position above the rank of instructor at Chicago until Karen Uhlenbeck became professor there in 1982. Prominent women mathematicians in the same generation also include Olga Taussky-Todd ${ }^{2}$ (1930, Vienna); Mina Rees $^{3}$ (1931, Chicago); Dorothy Bernstein (1939, Brown), the first woman president of the MAA; and Julia Robinson ${ }^{4}$ (1948, Berkeley), the first woman president of the AMS.

Margaret A. Readdy is professor of mathematics at the University of Kentucky. Her email address is margaret. readdy@uky. edu.

Christine Taylor is senior lecturer of mathematics at Princeton University. Her email address is ctay 1or@math . princeton . edu.

Readdy and Taylor are, respectively, current and former program managers of the Women and Mathematics Program at the Institute for Advanced Study. Readdy and Taylor wish to thank Jeanne LaDuke for advice, expertise, and help, both historical and editorial.

${ }^{1}$ See the article "Winifred Edgerton Merrill: 'She Opened the Door'” in the April 2012 Notices www.ams.org/notices/201204/ rtx120400504p.pdf

2See the article "In Memoriam: Olga Taussky-Todd" in the August 1996 Notices www . ams . org/notices/199608/taussky . pdf.

${ }^{3}$ See the article "Mina Spiegel Rees (1902-1997)" in the August 1998 Notices www . ams . org/notices/199807/memoria1-rees. pdf.

For permission to reprint this article, please contact: reprint-permission@ams.org.

DOI: http://dx.doi.org/10.1090/noti1653

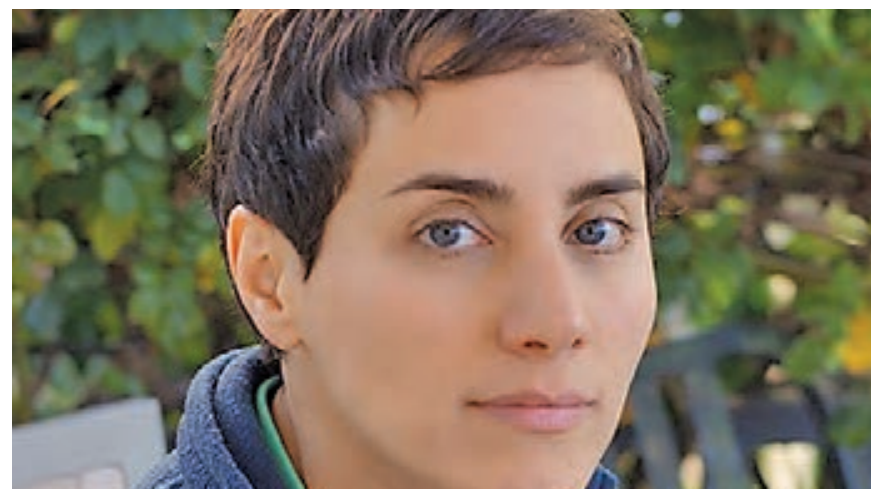

Maryam Mirzakhani (1977-2017)

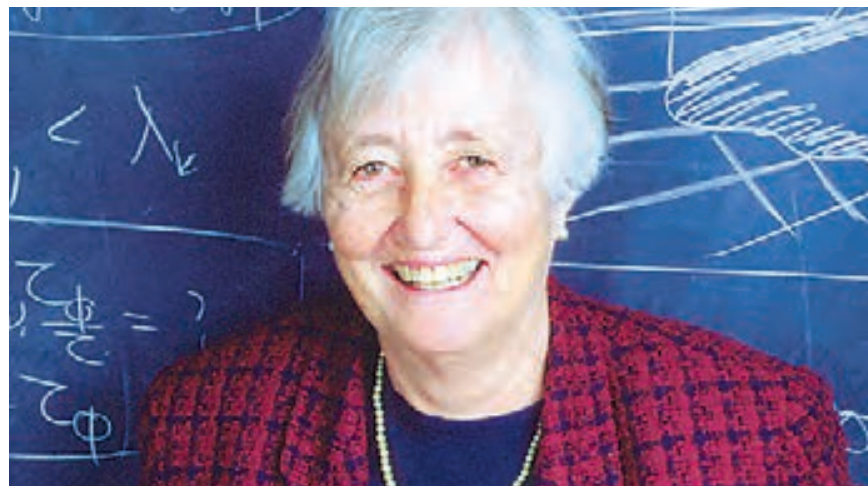

Cathleen Synge Morawetz (1923-2017)

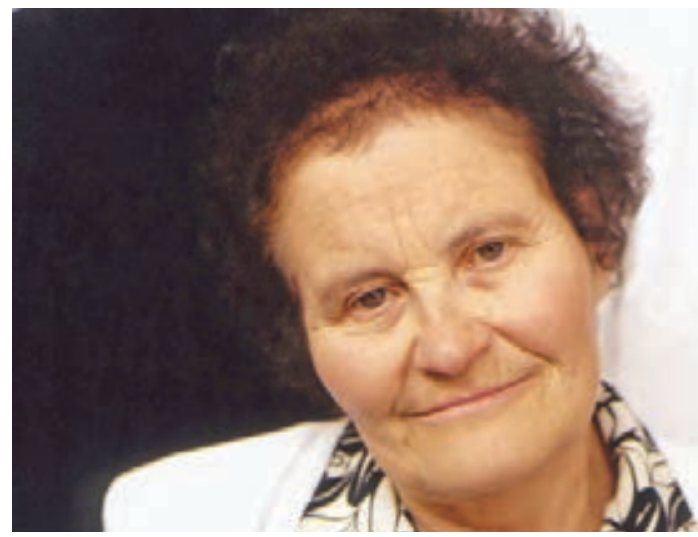

Marina Ratner (1938-2017) 
Generally, the women who earned doctorates in mathematics before WWII did their work with distinguished advisors, but had difficulties when it came to finding jobs, especially at institutions comparable to those where they had received their education. Women's colleges and coeducational private colleges were often more supportive and nurturing.

After WWII, the percentage of women earning PhDs in mathematics dropped dramatically and only returned to its earlier levels in the 1980s. Contemporary women mathematicians come from a variety of backgrounds, as exemplified by the accompanying profiles and this $\mathrm{No}$ tices cover. In recent years, women mathematicians have entered the American workforce from every continent. Within the US, women from diverse social, economic, and racial backgrounds have slowly found their footing and risen to the forefront in mathematics. We take this opportunity to honor some of them.

While much progress has been made in the last thirty years in training and retaining women in mathematics through governmental and institutional policies, the woefully low percentage of women with prestigious awards and recognitions highlights the task ahead for the mathematical community.

\section{In Memoriam:}

In the summer of 2017, the mathematical community mourned the passing of three mathematical giants:

Maryam Mirzakhani, ${ }^{5}$ who won the Fields Medal in 2014, worked in Teichmüller theory, hyperbolic geometry, ergodic theory, and symplectic geometry;

Cathleen Synge Morawetz, ${ }^{6}$ who received the National Medal of Science in mathematics in 1998, the AMS Leroy P. Steele Prize for Lifetime Achievement in 2004, and was AMS President 1995-1996, worked in partial differential equations; and

Marina Ratner, best known for Ratner's theorems on unipotent flows on homogeneous spaces, which she proved in her 50s, worked in ergodic theory.

\section{ABOUT THE EDITORS}

Margaret A. Readdy works in algebraic combinatorics. Readdy spent a sabbatical at MIT in 2006-2007, was a member of the Institute for Advanced Study in 2010-2011, and spent a sabbatical and research leave at Princeton University in 2014-2015.

Christine Taylor studied manifolds with exceptional holonomy in graduate school and more recently has worked on evolutionary game theory.

\section{Photo Credits}

Photo of Maryam Mirzakhani courtesy of Jan Vondrák, 2012. Photo of Cathleen Morawetz by James Hamilton.

Photo of Marina Ratner authored by George M. Bergman. Source: Archives of the Mathematisches Forschungsinstitut Oberwolfach.

Photo of Margaret A. Readdy courtesy of Theodore Ehrenborg. Photo of Christine Taylor courtesy of Christine Taylor.

EDITOR'S NOTE. Memorials for Mirzakhani, Morawetz, and Ratner are planned for future issues.

\footnotetext{
${ }^{4}$ See the article "Julia Robinson and the Hilbert Tenth Problem" in the May 2008 Notices www.ams.org/notices/200805/ tx080500573p.pdf.

${ }^{5}$ Stanford Memorial: www . youtube . com/watch?v=IUfB2HadIBw \&feature=youtu.be.

Harvard Memorial: www . youtube . com/watch?v=HUBnzTTQ5jk

${ }^{6}$ Courant Memorial: cims.nyu.edu/conferences/cath1eenmorawetz-celebration/index.htm1.
} 


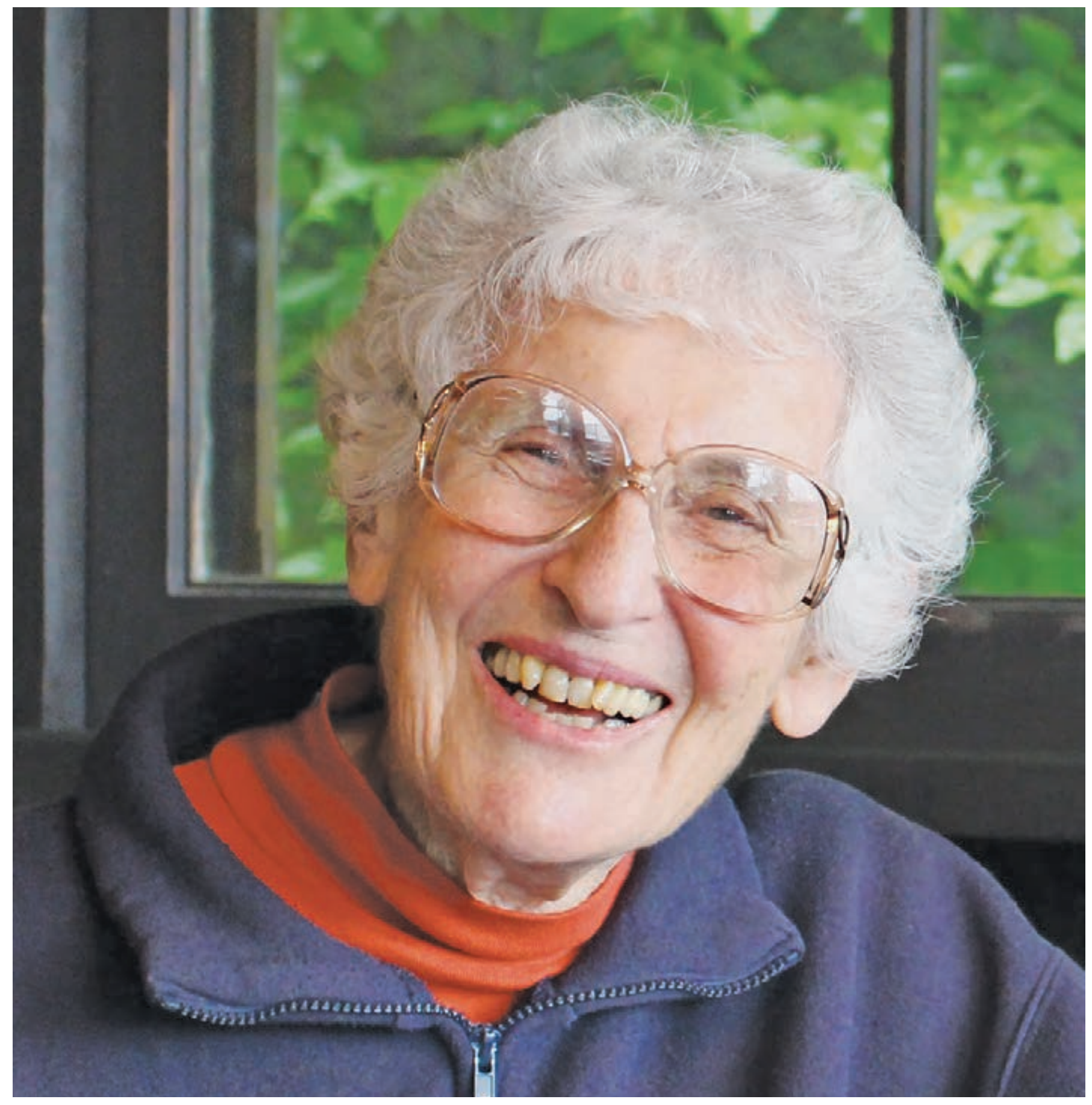


WOMEN'S

HISTORY

MONTH

\section{Synopsis of Research}

In Joan Birman's first formal meeting with her PhD thesis advisor, Wilhelm Magnus, she learned that the mapping class group of the twice-punctured torus was well understood and that she should think about how it might change if there were three punctures. This tiny start eventually led Birman into an area of research that starts with mapping class groups of surfaces, and the combinatorics of curves on surfaces, and moves out to encompass the topology, geometry, and group theory of 3- and 4-manifolds. Braid groups arise in this setting as the mapping class group of the $n$-times punctured disk. Early in Birman's career, she wrote Braids, Links and Mapping Class Groups, which had a wide readership. As it happens, braids are present in widely different parts of mathematics. As one dramatic example, the Jones polynomial, a knot-type invariant, was first discovered via apparently unrelated work in operator algebras. Gradually, it became clear that braiding had made its appearance through the way in which one type $\mathrm{II}_{1}$ factor sat inside another.

\section{Biography}

I was a math major in college, and after graduation I chose to work in industry (at what was then called "systems analysis"), full time for nine years and part time for four years. I began graduate studies with evening courses after my third child was born and received my $\mathrm{PhD}$ from the Courant Institute of NYU in 1968, exactly twenty years after my BA. My husband, Joseph L. Birman, professor of physics at NYU, was highly supportive of every step I took, and the confidence I gained from his support, plus the free tuition I obtained as an NYU spouse, were essential parts of that picture. There were very few women in math in the early 1970s, and that plus my age at graduation certainly caused problems, e.g., I received exactly one job offer (for a position at Stevens Institute of Technology), and it came a few weeks before fall classes began! Nevertheless, with that job in hand my career was on its way.

I think that the combination of teaching and research is an excellent one. There was always at least one student in the classes I taught who asked sharp questions and kept me on my toes. My research continued and attracted interest. Among the seminar talks I gave was one at Professor Ralph Fox's Princeton topology seminar. That talk led to an invitation to visit Princeton. ${ }^{1}$ It was not a traditional postdoc at all, just a one-semester visiting appointment with a two-course teaching load, and the logistics required a three-day/week commute between New Rochelle and Princeton: however, it made a huge difference in my career. The course that I gave that semester became a research monograph, with a list of open problems at the end, each one a problem I encountered as I prepared those lectures. The book had a wide readership and eventually led to a move in 1973-4 from Stevens to a tenured position at Barnard-Columbia. The stimulation of belonging to a fine department, with its seminars and colloquia, highly talented postdocs, and excellent graduate students helped my growth as a mathematician. I never felt that I knew enough mathematics, and that is true to this day.

\section{Advice to Young Women}

I think that the most important thing is to identify work that you love. I really love mathematics. As regards to balancing the needs of family and work, think carefully about what is important to you and what will work for you. I note that this is a major issue for most women mathematicians. I note that another major issue for potential mathematicians, male and female, is to not be intimidated by people who understand material faster than you understand it. To be sure, speed helps, but it is not fundamentally important.

\section{Photo Credit}

Photo of Joan Birman $\subset$ Ken Birman, 2014.

\footnotetext{
$\overline{{ }^{1} \text { See also "Early Women Mathematicians in Princeton" on page } 304 .}$
} 
Melody Chan

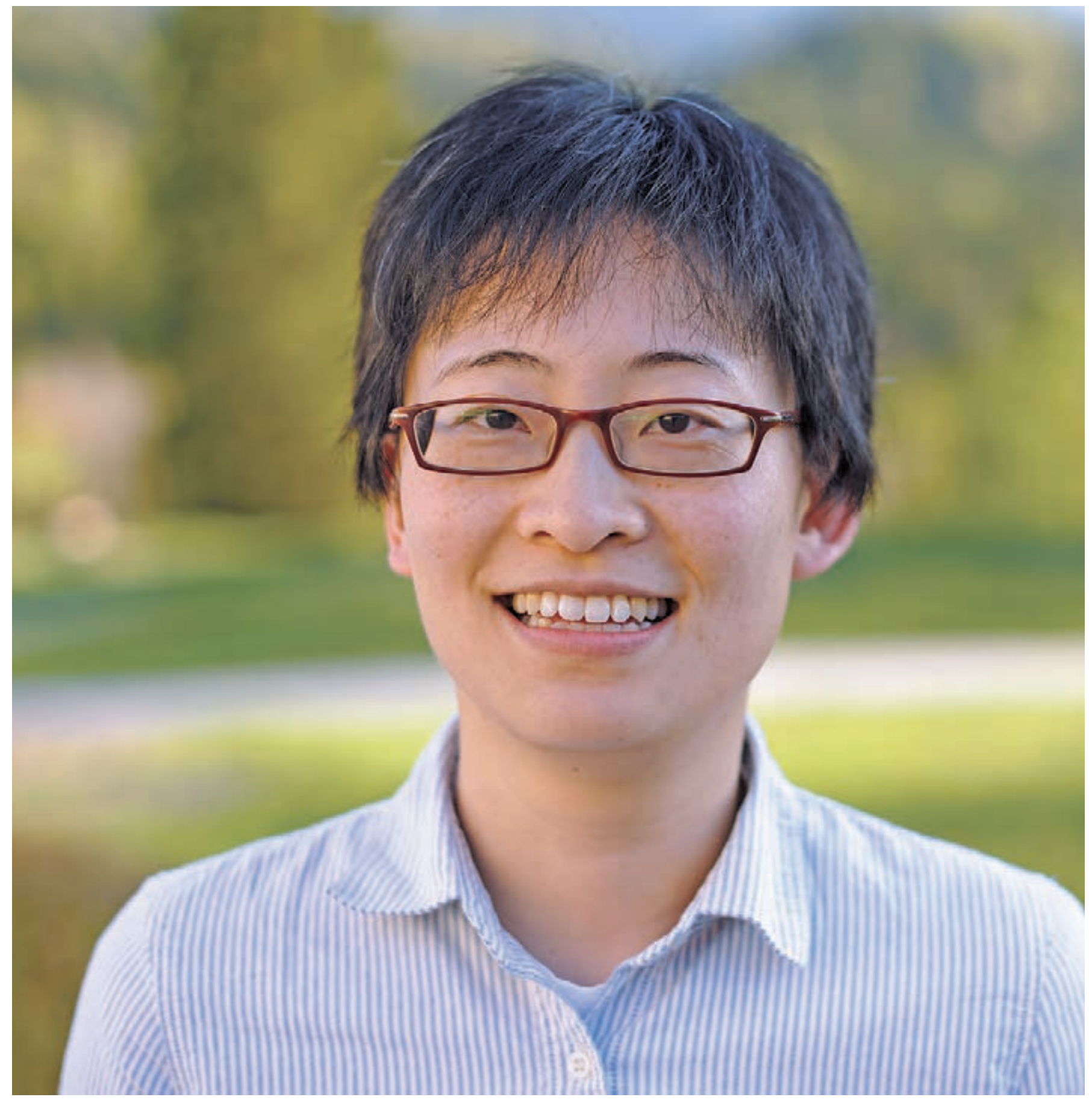


WOMEN'S

\section{HISTORY}

MONTH

\section{Synopsis of Research}

Melody Chan is a mathematician working in the fields of tropical geometry, combinatorial algebraic geometry, and combinatorics. A common thread in her research is using degeneration techniques in algebraic geometry to study curves and their moduli spaces. Tropical geometry is a modern such technique, in which algebraic objects may be regarded as degenerating to entirely combinatorial ones. Chan has authored or co-authored over twenty publications, and has made notable contributions on the topic of tropical curves and their moduli spaces, especially combinatorial, topological, and stack-theoretic foundations.

\section{Biography}

Melody Chan grew up in the suburbs of New York. She juggled a dual love of math and music: after graduating from high school, she went to the Juilliard School at the age of sixteen spending a year studying violin with Itzhak Perlman and Dorothy DeLay. Subsequently she attended Yale University and received her $\mathrm{PhD}$ from the University of California Berkeley in 2012, advised by Bernd Sturmfels. She was an NSF Postdoctoral Fellow at Harvard from 2012 to 2015 before beginning her current position as an assistant professor at Brown University. Chan's research has been supported by recent grants from the National Security Agency, from the National Science Foundation, and by the Henry Merritt Wriston Fellowship, Brown University's highest award for junior faculty for research and teaching. She has also maintained and nurtured a commitment to teaching and mentoring in mathematics since graduate school.

\section{Advice to Young Women}

Do examples! Try to do as much mathematics as you can standing at the board, writing things down, and explaining them to people.

\section{Photo Credit}

Photo of Melody Chan courtesy of Joseph Rabinoff. 


\section{Alice Chang}

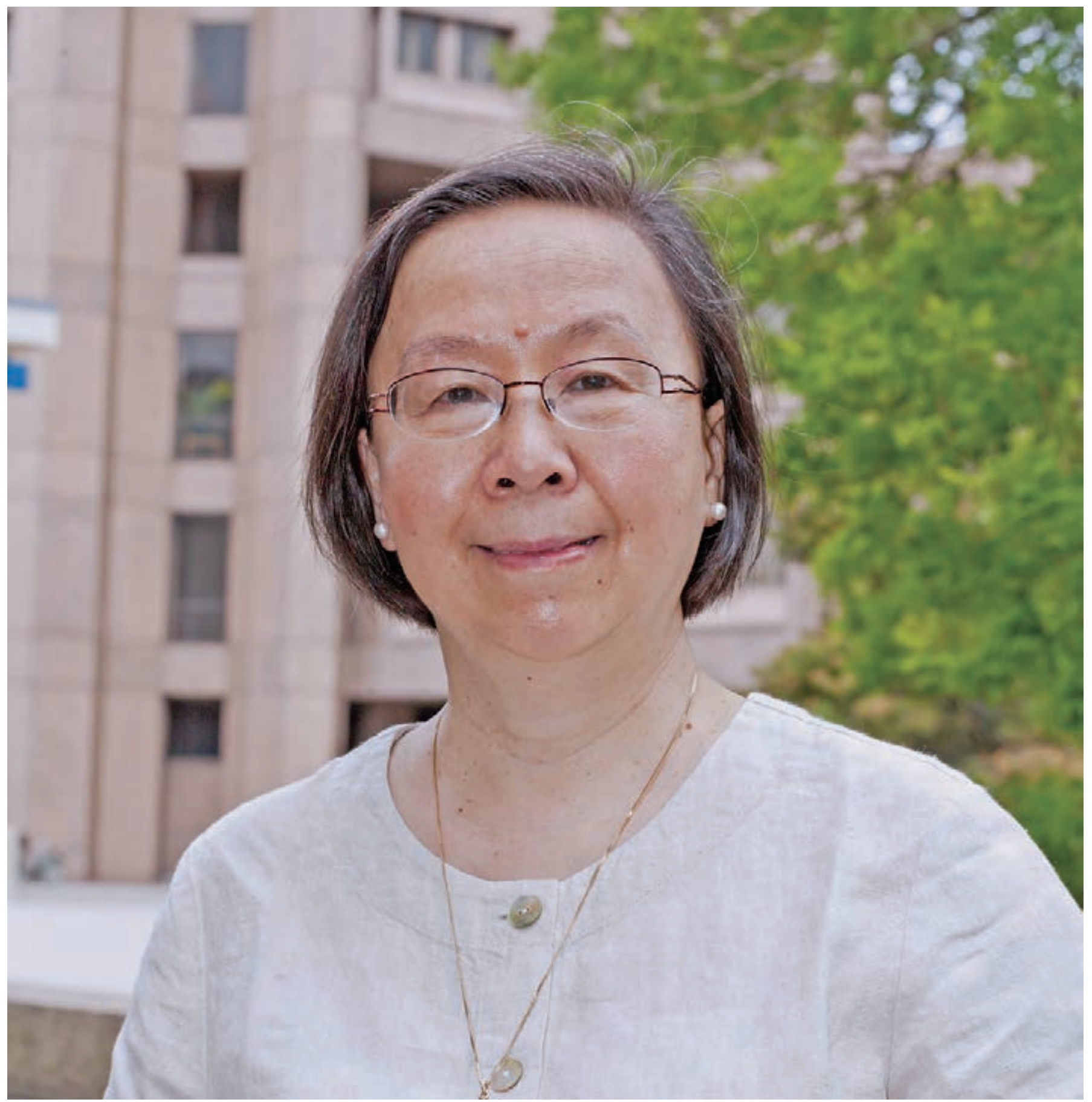




\section{WOMEN'S}

\section{HISTORY}

MONTH

\section{Synopsis of Research}

Alice Chang started her research as a classical harmonic analyst. Her research interests have gradually shifted to problems in geometric analysis, mainly in applying PDE methods to study problems in conformal geometry. Her major contributions include applying PDE techniques to study the Gauss-Bonnet integrand and other conformal invariant quantities on real 4-manifolds. These PDEs are of higher order (in particular 4th order) and fully non-linear (of Monge-Ampère type). One of her goals is to classify the diffeomorphism type of a class of 4-manifolds under some conformally invariant curvature conditions-modestly continuing the great achievement of the geometry in the last decade in classifying the diffeomorphism type of 3-dimensional manifolds.

\section{Biography}

I was born in China, grew up in Taiwan, and have spent most of my life in the US. I think I benefited a lot from my multicultural background. I have lived the life of an academic and a research mathematician and feel I have been really lucky in life. I have a wonderful family: my husband Paul Yang is also a mathematician, a colleague and a co-worker; I have a son and a daughter, both of whom I am proud of. I work in a profession I truly enjoy, I live in a stimulating environment, and I have been treated well in all the places I have worked. One thing I find truly rewarding is supervising $\mathrm{PhD}$ students and watching them grow in the profession; many of them have become close, personal friends of mine. I am profoundly honored in the profession, having been elected to NAS, AAAS, Academia Sinica in Taiwan, and Fellow of the AMS, and having served as chair of the mathematics department at Princeton during 2010-2013.

\section{Advice to Young Women}

In my career I have benefited a lot from collaboration with colleagues. My advice for young women is to pursue your passion with a group of friends with similar interests.

\section{Comments on Women's History Month}

We have come a long way and still have a long way to go! Despite the progress, women still face more struggles between family and career. But looking into the future, time is on our side: gender equality is becoming more and more the norm and we are healthier, live longer, and can accomplish more.

Technology and computer science play increasingly important roles in today's world. I think it is important that more women get into the fields of science and technology; this is a way to make a good living and to have the chance to push the advancement of the world forward.

\section{Photo Credit}

Photo of Alice Chang courtesy of Sun-Yung Alice Chang. 


\section{Maria Chudnovsky}

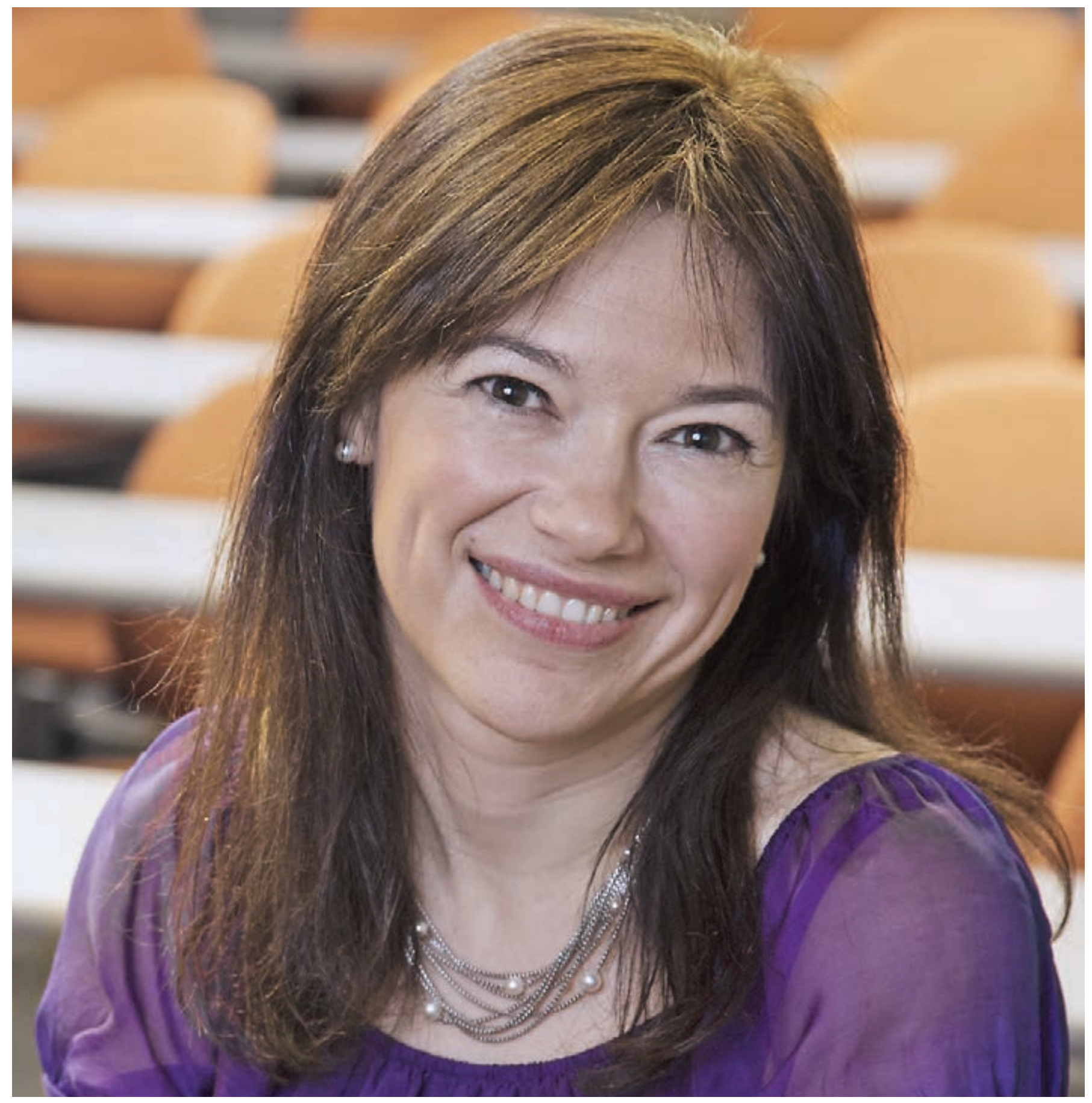




\section{WOMEN'S}

\section{HISTORY}

MONTH

\section{Synopsis of Research}

Maria Chudnovsky works in graph theory. She tries to understand the structure of graphs defined by certain properties, and then answer questions about these graphs using the structural information. As a graduate student, she was a part of a team of researchers that proved the Strong Perfect Graph Theorem, thus settling a forty-year-old conjecture, which proposed a certain characterization of graphs that behave especially nicely with respect to graph coloring. Since then she has continued to work on questions relating graph structure and coloring, studying both the theoretical and the algorithmic aspects of the problem. Chudnovsky is currently working on several exciting projects, such as determining the complexity of coloring a graph with various induced subgraphs excluded, trying to better understand the structure of perfect graphs, and more.

\section{Biography}

Maria Chudnovsky received her BA and her MSc from Technion, and her PhD from Princeton University in 2003. Currently she is professor at Princeton. Before returning to Princeton in 2015, she was Veblen Research Instructor at Princeton University and the IAS, assistant professor at Princeton, Clay Mathematics Institute Research Fellow, and Liu Family Professor of Industrial Engineering and Operations Research at Columbia University. Her research interests are in graph theory and combinatorics. She is an editorial board member of the Journal of Graph Theory. For her work on the Strong Perfect Graph Theorem, Chudnovsky was awarded the Ostrowski Foundation research stipend in 2003 and the prestigious Fulkerson Prize in 2009. She was also named one of the "brilliant ten" young scientists by Popular Science. In 2012 Chudnovsky received the MacArthur Foundation Fellowship. In 2014, she was an invited speaker at the International Congress of Mathematicians.

\section{Advice to Young Women}

Her advice to young women and everyone else is: Don't give up before you absolutely have to, or want to.

\section{Photo Credit}

Photo of Maria Chudnovsky courtesy of Maria Chudnovsky. 


\section{Carina Curto}

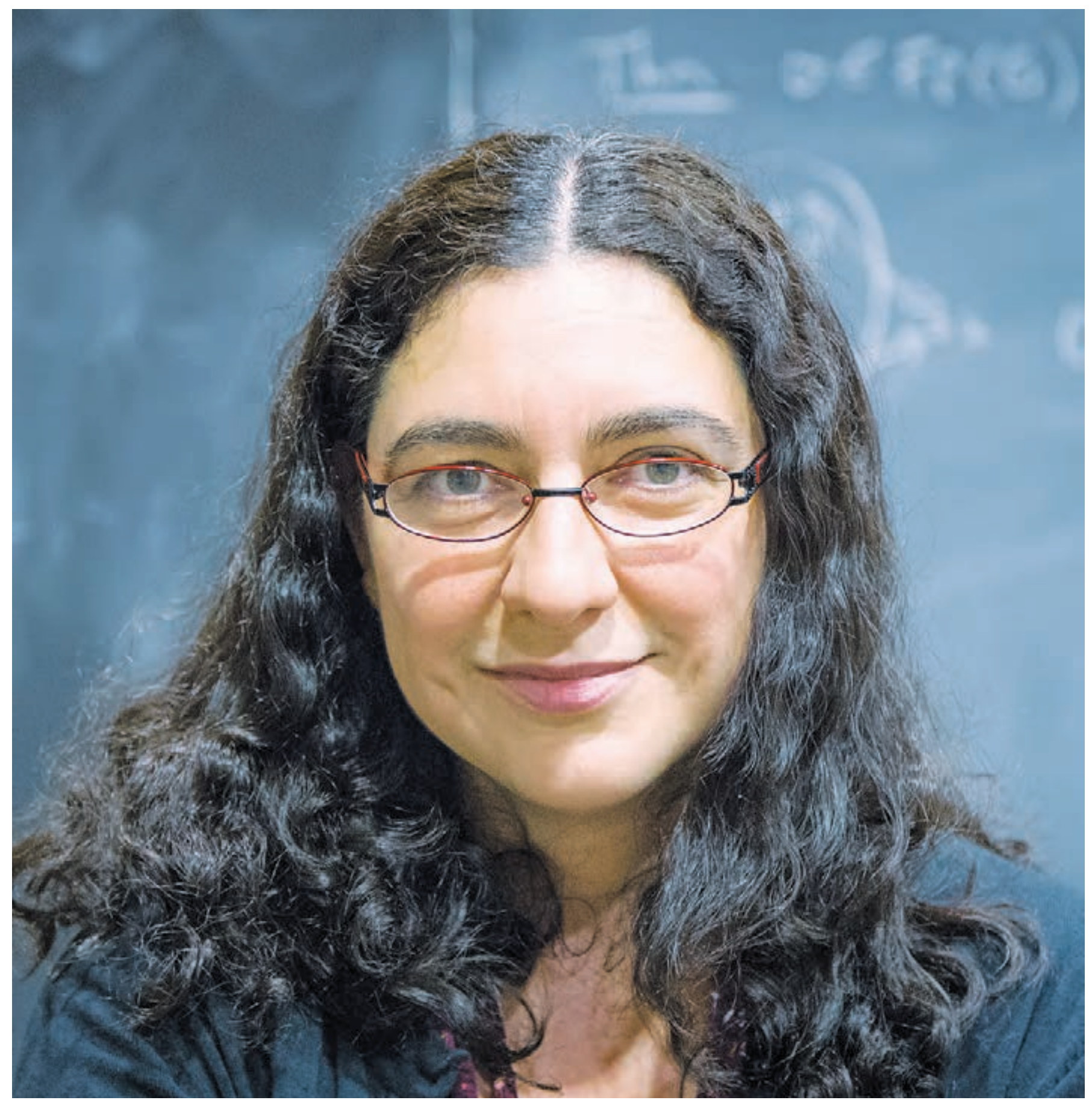




\section{WOMEN'S}

\section{HISTORY}

MONTH

\section{Synopsis of Research}

Carina Curto's research lies at the interface of neuroscience and mathematics. She is fascinated by fundamental questions in neuroscience, such as:

How do neurons encode and process information about the outside world?

How are memories stored and retrieved in neural networks, and what kinds of architectures underlie the rich and varied dynamics observed in the brain?

As a mathematician, Curto works on developing models that capture experimentally observed phenomena but are simple enough to admit theoretical analysis. She proves theorems about neural networks and neural codes and uses computer simulations to build intuition and play with examples. She also develops novel data analysis techniques to address the challenges that arise in working with biological data. Her collaborators include neuroscientists and mathematicians of different backgrounds. Many unexpected areas of mathematics have been useful in her work, ranging from applied algebra and topology to graph theory, dynamical systems, and discrete geometry. Curto hopes to eventually write a book on neural networks and neural codes, with an eye towards young mathematicians who are interested in applications and have a fondness for algebra, topology, and combinatorics.

\section{Biography}

I grew up in Iowa City, Iowa, which is home to the Iowa Writers' Workshop. As a child, I always thought I would either become a writer or a theoretical physicist. My father was a mathematician, so that was not glamorous enough for my childhood dreams. I also grew up speaking Spanish, and my parents instilled in me a strong sense of our Argentine background. When I was in high school, I studied everything that interested me, taking as many classes as I could at the University of Iowa. The state law at the time allowed high school students to take college credits for free in any subject not offered at their school. Most often, this was used for advanced math classes-but I milked it, adding courses in physics, economics, computer science, writing, French literature, and Italian. Somehow, I also found time to be a serious tennis player and member of the debate team.

My college years at Harvard were more focused, and it was there that I finally discovered my love for mathematics and its deep connections to physics. By the time I got to graduate school, I was on a path to becoming a string theorist. Halfway through my $\mathrm{PhD}$, however, I became disillusioned with string theory and fell in love with neuroscience. This sent my career on a very different path. After graduating, I spent three years as a postdoc in a neuroscience lab at Rutgers. It was an exhilarating experience: a complete cultural immersion into a world of science I had barely known existed when I first entered graduate school. Eventually, I returned to math as a mathematical neuroscientist. I'm currently a tenured math professor at Penn State University. I've been awarded a Sloan Research Fellowship and multiple grants from NSF and NIH. I live in State College with my husband-who is also a frequent collaborator-and our two kids.

\section{Advice to Young Women}

Dream big and make your dreams a serious priority! And don't worry too much about pleasing your family and mentors by "following the rules." Great research is like great art: it takes courage, and a conviction that what you do matters-even if others don't initially see the value.

Photo Credit

Photo of Carina Curto by Carley LaVelle, Penn State. 
Ingrid Daubechies

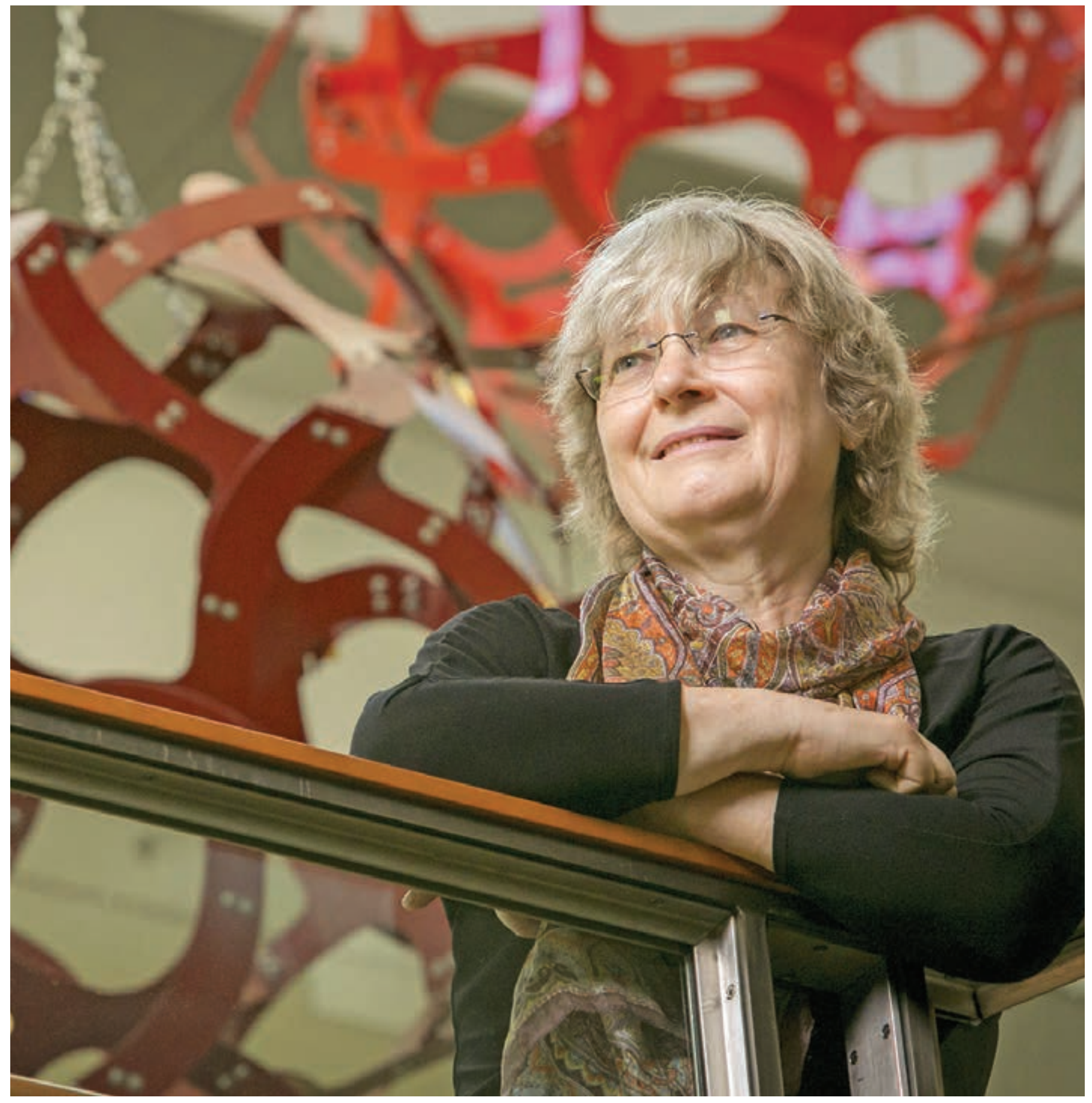


WOMEN'S

HISTORY

MONTH

\section{Synopsis of Research}

Ingrid Daubechies works on mathematics applied to the sciences and engineering, and beyond. Daubechies started out as a mathematical physicist, with both $\mathrm{BS}$ and $\mathrm{PhD}$ degrees in physics. She first worked on rigorous results in quantum mechanics, but then found that she was also interested in applying the mathematical techniques she had learned during her $\mathrm{PhD}$ training to other questions, more related to engineeringand presto-she became an applied mathematician.

Daubechies got interested in wavelets in the early 1980s. The wavelet transform had then just been formulated as an alternative, with very interesting properties, to the windowed Fourier transform (aka, coherent state representation in quantum mechanics) for the analysis of time-dependent signals. It turned out that wavelets were connected to many other developments in harmonic analysis, computer science, and electrical engineering, but that synthesis came later.

In 1987, Daubechies' work on wavelets led her to construct orthonormal wavelet bases for which the generating wavelet combined smoothness with being supported on an interval - a result that many had believed to be impossible. The construction was completely motivated by applications: other smooth wavelet bases all had infinite support and thus had to be truncated for numerical applications. Because she never believed that applications necessarily imply that mathematical elegance would be sullied or corrupted by implementation details, Daubechies had a very different approach to the construction, which turned out to work. This work is probably still the one for which Daubechies is best known; it certainly is the most cited.

Over the years, Daubechies has worked with scientists and engineers in many different fields, often but not always involving wavelets-typically on signal analysis or representation, sometimes combined with so-called inverse problems. These fields include neuroscience, geophysics, optics, biological morphology, medicine, and most recently art history. ${ }^{1}$

\section{Biography}

Ingrid Daubechies earned her $\mathrm{PhD}$ in theoretical physics from Vrije Universiteit Brussel. She is best known for her breakthroughs in wavelet research and her contributions to digital signal processing. Some of the wavelet bases she constructed have become a household name in signal analysis; they, and other computational techniques she and collaborators developed, have been incorporated into the JPEG2000 standard for image compression. Apart from her work on wavelets, Daubechies has contributed to other seminal advances in time-frequency analysis.

Her career has seen many impressive firsts: Daubechies was the first female full professor of mathematics at

\footnotetext{
${ }^{1}$ See "Reunited: Francescuccio Ghissi's St. John Altarpiece" in the January 2017 Notices www. ams . org/pub7ications/journa7s/ notices/201701/rnoti-p8.pdf.
}

Princeton, the first woman to receive the National Academy of Sciences Award in Mathematics in 2000, and the first woman president of the International Mathematical Union (2010-2014).

In addition to her commitment to educating and mentoring the next generation of mathematicians, Daubechies continues to break new ground in mathematics research and expand its impact outside of her discipline, focusing on the analysis of signals and inverse problems in a wide range of settings, with applications ranging from fMRI and geophysics to paleontology and the study of fine art paintings.

\section{Advice to Young Women}

In all my work, I have been motivated by trying to understand, in mathematical terms, what was going on. I believe mathematicians can be enormously valuable in interdisciplinary collaborations, because our mathematical training has given us tools for mathematically sophisticated frameworks and techniques that can really help in thinking in an abstractly well-structured way about complex questions in other fields. I have also learned not to underestimate the sophistication of thinking of my non-mathematical collaborators, even when they don't necessarily have the mathematical vocabulary or semantics to formulate what guides them. My job is, in part, to recognize and then unravel these trains of thought, a process that takes time, and that can only work if both parties are patient communicators. It is my job then to take them further with the appropriate mathematics. When I am lucky, the results are interesting mathematically and also feed back to the application in an interesting, non-trivial way. I have found this a fulfilling way to build a career, even if it is not quite conventional. Many of my students have found ways in making this work for their careers as well, in a diversity of directions that I find very gratifying.

I would encourage any young mathematician thinking of working on applications to learn as much pure mathematics as possible, limited only by appetite and time, not by how applicable they think it might be. I believe that I have used in my own career all the mathematics I understand, I just wish I knew more, and that I still had the time to learn more. On the other hand, I have also found that great joy comes from working with others. Experiencing the give-and-take of half-baked ideas that then are given substance through the collaborative effort is exhilarating.

\section{Photo Credit}

Photo of Ingrid Daubechies courtesy of Les Todd: Duke Photography. 
Irene Fonseca

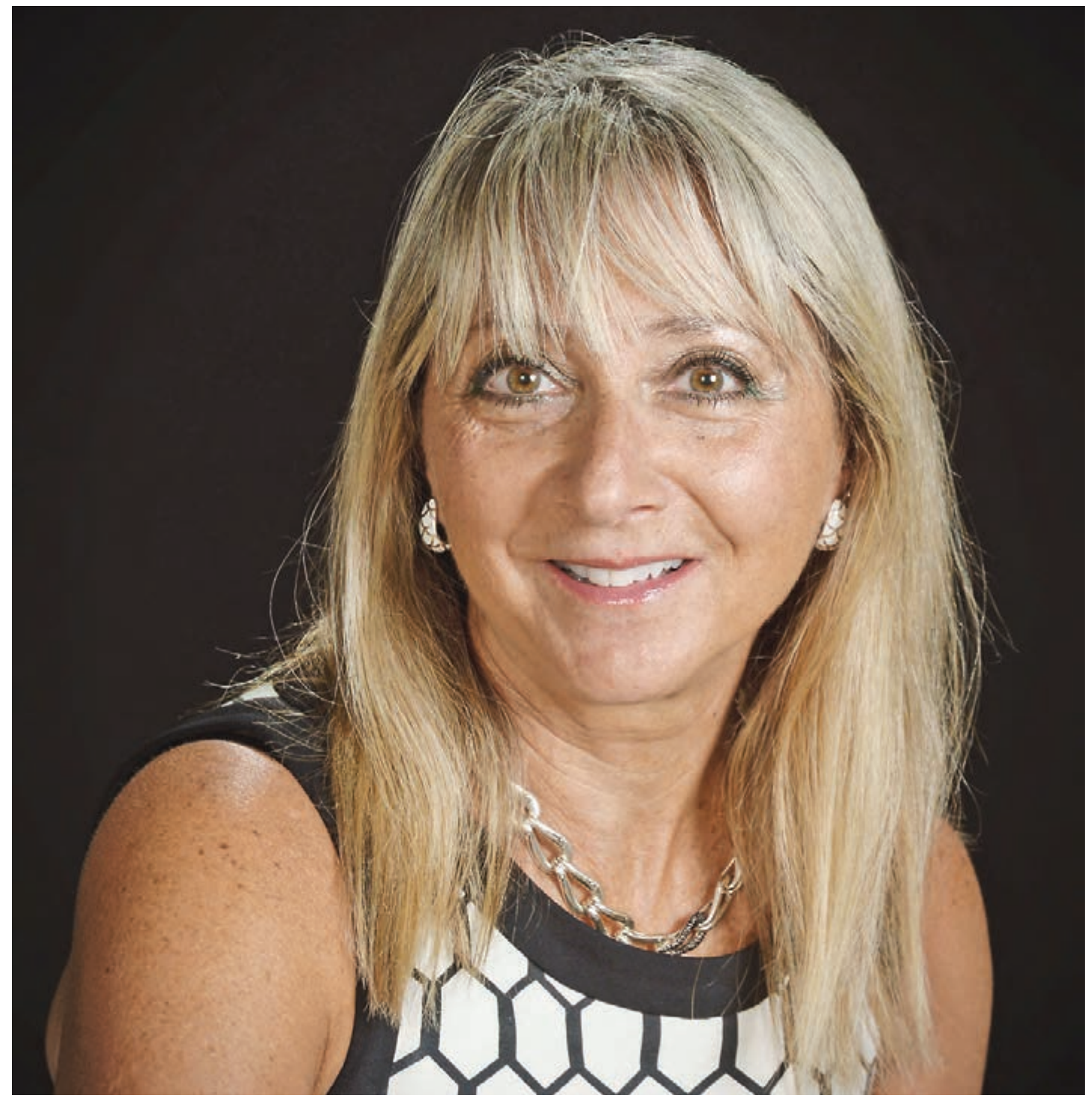


WOMENS

\section{HISTORY}

MONTH

\section{Synopsis of Research}

Irene Fonseca's main contributions have been in the variational study of ferroelectric and magnetic materials, composites, thin structures, phase transitions, and in the mathematical analysis of image segmentation, denoising, detexturing, registration, and recolorization in computer vision. Her research program continues to explore modern methods in the calculus of variations motivated by problems arising from materials science and imaging science.

\section{Biography}

Irene Fonseca has supervised $14 \mathrm{PhD}$ students and mentored 36 postdoctoral fellows. She is a Fellow of the American Mathematical Society (AMS) and a Fellow of the Society for Industrial and Applied Mathematics (SIAM). Fonseca was SIAM president in 2013 and 2014. She is a Grand Officer of the Military Order of Saint James of the Sword (Grande Oficial da Ordem Militar de Sant'Iago da Espada, Portuguese Decoration). She serves on fifteen editorial boards, including Advances in Calculus of Variations, ESAIM:COCV (SMAI), Journal of Nonlinear Science, Le Journal de l'Ecole Polytechnique, M3AS, and SIAM Journal on Mathematical Analysis. She is a member of several advisory and scientific boards of research centers and institutes, including the IMA and SAMSI; participates in international prize committees; and is on review and evaluation panels of multiple universities in the US and abroad.

\section{Advice to Young Women}

- Find a good advisor/mentor who has availability to see you periodically and frequently.

- Get involved in activities that will allow you to network with other students in math-related fields, such as math clubs and SIAM student chapters.

- Go to workshops, conferences, summer schools, and when appropriate showcase your work through posters, contributed talks, etc.

- Have fun doing mathematics. Let it be a passion.

- Be confident in your math skills, don't hesitate to ask questions, and be assertive when you think you know the answer.

\section{Photo Credit}

Photo of Irene Fonseca courtesy of Irene Fonseca. 


\section{Carolyn Gordon}

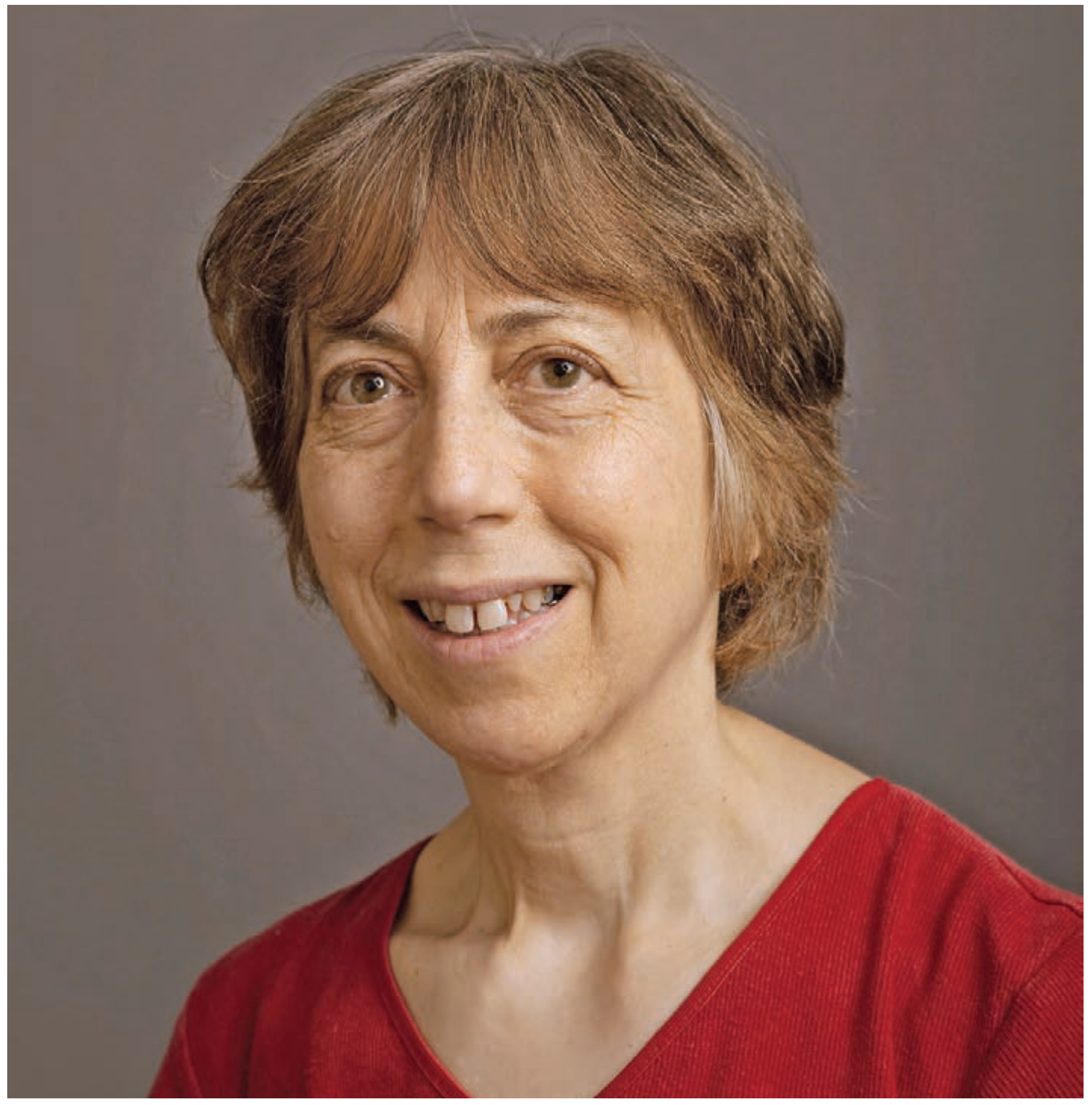




\section{WOMEN'S}

\section{HISTORY}

MONTH

\section{Synopsis of Research}

Carolyn Gordon's research is in the area of Riemannian geometry, focusing on inverse spectral problems and on homogeneous spaces. Inverse spectral problems ask the extent to which geometric or topological properties of an object such as a vibrating membrane or, more generally, a Riemannian manifold are encoded in spectral data. For example, Gordon, along with David Webb and Scott Wolpert, gave a negative answer to Mark Kac's question, "Can one hear the shape of a drum?"

\section{Biography}

When I was growing up, it was assumed that women would go to college primarily to get their "Mrs Degree." I never considered an academic career-or any career for that matter-until my undergraduate algebra professor, Stephen Piper, asked me if I had plans for graduate school. Just the question itself both ignited a dream and helped give me the confidence to pursue it. Soon after, I entered a $\mathrm{PhD}$ program at Washington University, later returning as a faculty member. I was fortunate to have my twobody problem solved before it existed. I met my husband David Webb when he also began a tenure-track position at Washington University. A few years later we moved to Dartmouth College. My greatest joy has been parenting our daughter Annalisa. She was often my mentor as well as my child, especially when I stretched well beyond my comfort zone in taking on the presidency of the AWM during her elementary school years. Some honors (mostly traceable back to a ten-minute contributed talk at a regional AMS meeting early in my career) have included a Chauvenet Prize with co-author David Webb, an endowed professorship, and becoming a Fellow of the AMS and of the AAAS. Perhaps the honor (if not the title!) that makes me most proud is a Vagina Warrior Award for mentoring, as it was presented by students.

\section{Advice to Young Women}

My first suggestion to younger women is to take every opportunity to present your work and talk to other mathematicians. You never know when a mentor may appear. Indeed, my interest in spectral geometry arose from a suggestion by Rich Millman, a member of the tiny audience during that early-career ten-minute talk at a regional AMS meeting. His comments not only changed my research trajectory but, as a consequence, opened many new career opportunities for me. Secondly, while I've "known" throughout my career that I'm an impostor, I've come to realize that if I haven't been found out yet, I probably never will be! So if you too feel like an impostor, know that you're not alone and just keep going!

\section{Comments on Women's History Month}

I'm delighted to see this celebration of Women's History Month in the Notices and honored to be included. My generation of women has had many more opportunities than those before us, and we've seen considerable progress in our lifetimes. In the current national climate, it is essential to remember our history and ensure that we continue to move forward.

\section{Photo Credit}

Photo of Carolyn Gordon courtesy of Dartmouth College / Joseph Mehling. 


\section{Fan Chung Graham}

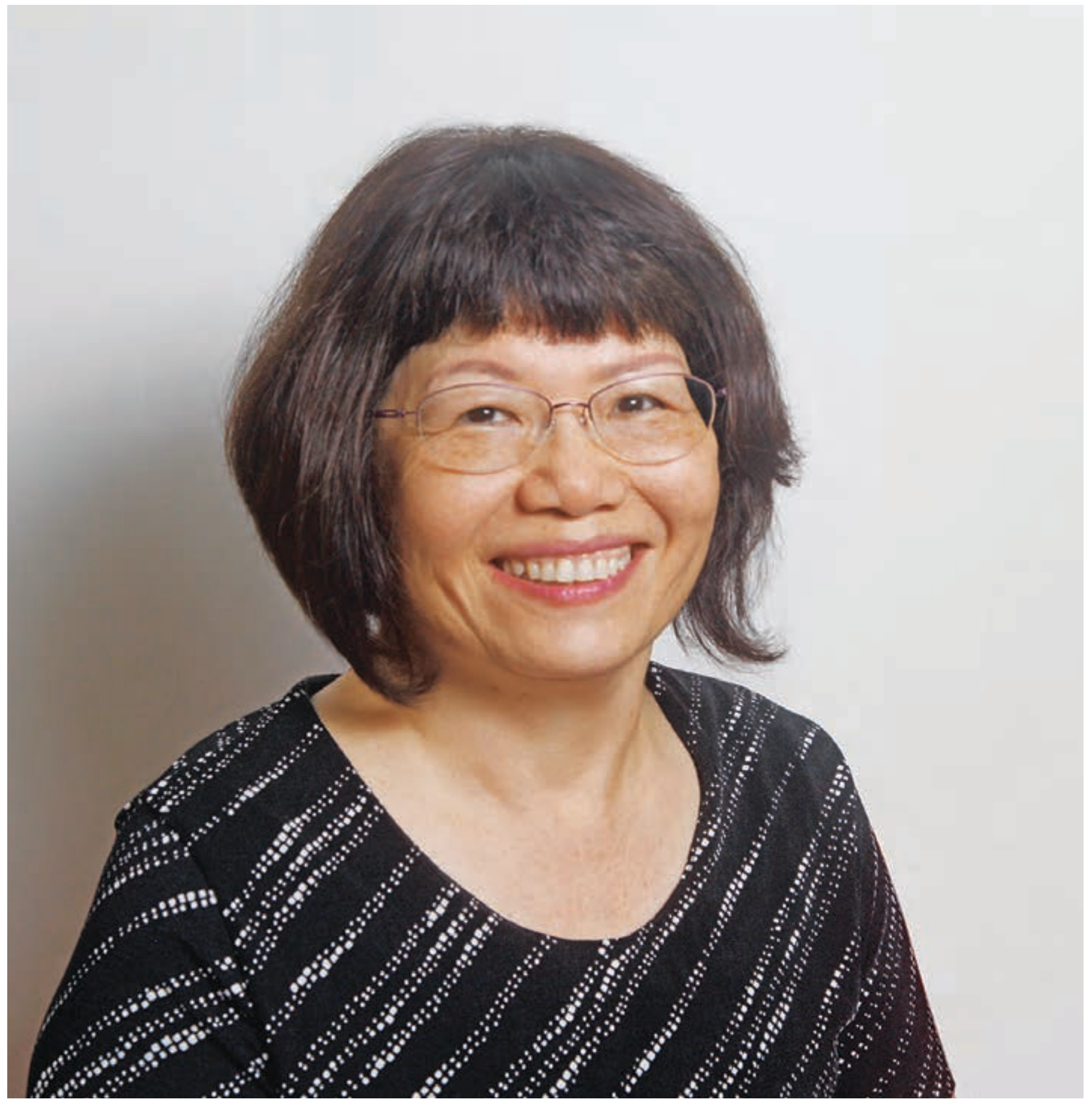




\section{WOMEN'S}

HISTORY

MONTH

\section{Synopsis of Research}

Fan Chung Graham's research interests are primarily in graph theory, combinatorics, and algorithmic analysis. She specializes in spectral graph theory, extremal graphs, the theory of quasi-randomness, and the probabilistic analysis of complex networks. Recently her work has included local graph algorithms for complex networks and random walks-based ranking algorithms.

Graham has made fundamental contributions in the following areas of mathematics:

- Spectral graph theory: Her research has been instrumental in establishing the foundations of spectral graph theory, introducing the normalized Laplacian, and establishing the basic relationship between the Laplacian spectral and numerous properties of graphs with general degree distributions.

- Random graph theory and complex networks: She has created a theory for treating random graphs that have arbitrary degree distributions, including power law graphs. This allowed her to analyze the behavior of the ubiquitous power law network in greater detail than has ever been possible previously.

- Quasi-random graphs: Her major contribution is the introduction and development of the concept of quasi-randomness. In a series of research papers with several co-authors, a large family of graph properties were shown to be equivalent. The set of equivalent quasi-random properties is surprisingly diverse and has been a seminal driver in the development of graph limits.

- Unavoidable graphs and universal graphs: A basic question in extremal graph theory is to find unavoidable patterns and structures in graphs with given density or distribution. A complementary problem is to find a smallest graph which contains every member of a given family of graphs as subgraphs. In work with Paul Erdős, she has determined the sizes and structures of unavoidable graphs and hypergraphs. Also, with several authors, she derives many elegant and surprising results on universal graphs. Her fundamental contributions in these areas of extremal graph theory have many applications in parallel computations.

- Ranking algorithms and clusters analysis in graphs: In recent years, she has done seminal work on the quantitative analysis for ranking algorithms in graphs. Instead of using usual graph distances, which does not work well for numerous information networks with the trait of small-world phenomenon, she introduced the mathematical analysis of quantitative ranking based on random walks. Her research on graph invariants derived from ranking has far-reaching impact not only in search algorithms and clustering analysis but also in the study of the geometry of networks.

\section{Biography}

Fan Chung Graham is a Distinguished Professor of Mathematics and professor of computer science and engineering at the University of California, San Diego. She is also the Paul Erdős Professor in Combinatorics.

Graham was awarded the Allendoerfer Award by the Mathematical Association of America in 1990. She is a member of the American Academy of Arts and Sciences, and she is an academician of Academia Sinica. She is a Fellow of the American Mathematical Society and of SIAM.

\section{Advice to Young Women}

Don't be intimidated!

I have seen many people get discouraged because they see mathematics as full of deep incomprehensible theories. There is no reason to feel that way.

In mathematics whatever you learn is yours and you build it up-one step at a time. It's not like a real-time game of winning and losing. You win if you benefit from the power, rigor, and beauty of mathematics. It is a big win if you discover a new principle or solve a tough problem.

\section{Photo Credit}

Photo of Fan Chung Graham by Ché Graham. 


\section{Rosemary Guzman}

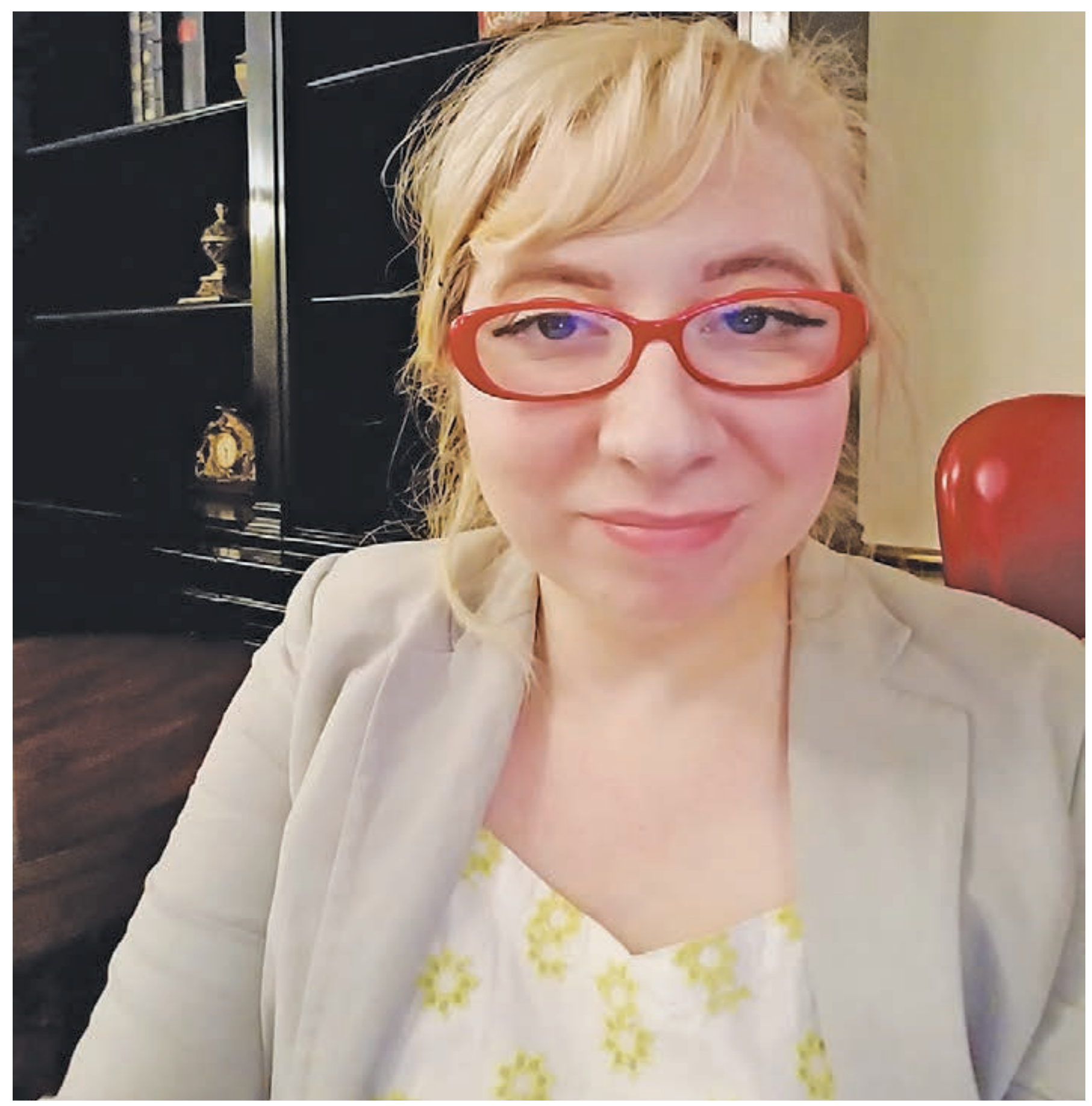




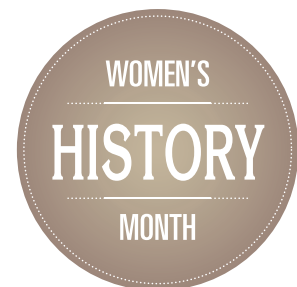

\section{Synopsis of Research}

Rosemary Guzman likes to explore questions in different areas of mathematics from a topological viewpoint. Her research interests are in hyperbolic 3-manifolds and geometric group theory, but co-advising several undergraduate research projects with her colleague Ruth Davidson-one in phylogenetics and another related to discrete Morse theory and persistence homology-provided rich and fulfilling questions that benefited from topological insights. Currently, Guzman has an ongoing project with Peter Shalen, which aims to extend for certain hyperbolic 3-manifolds some of the geometric-topological results previously developed by Shalen and Marc Culler. Guzman has enjoyed diversifying her research program in this way; some questions are long and hard, and others are a bit more attainable and also accessible to undergraduates. Being able to continue working and learning with experts as well as mentor and advise younger students has been constructive, both mathematically and personally.

\section{Biography}

I am currently an American Academy of University Women (AAUW) American Postdoctoral Fellow at the University of Chicago, with Benson Farb as my mentor. My previous NSF Alliance Postdoctoral fellowship at the University of Iowa afforded me the opportunity, thanks to a progressive chair, Dan Anderson, to teach an undergraduate research course that proved successful, an experience contributing to my becoming assistant director of the Illinois Geometry Lab. One of the most inspiring moments as a mentor came when a former calculus student at the University of Illinois asked me to serve as her academic sponsor for a technology entrepreneurship class, where she worked on the first project of her company, YouMatter Studios.

I still remain in touch with past students, some of whom are now graduate students in mathematics. A major highlight of my time at Iowa was a recognition provided by the graduating class of 2014: I was named a professor who had imparted a positive difference in students' lives. This was truly special because, as a first generation Mexican American having a vision impairment and raised in public housing in Chicago, I am now granted the chance to guide others who are on the pathway to academia as the first in their families. Socioeconomics can be an even more sensitive topic than gender or ethnicity, and it presents complex but hidden challenges. For instance, my early education was at a Chicago public school named by then-Secretary of Education William Bennett as an example of "the worst school in America." Losing a parent to a terminal illness paused my work for a time, but this loss evoked the willingness of others, in this case my PhD advisor, to take a chance on someone who experienced an interruption. While the conventional path to academia may seem narrowly defined, women and anyone traversing this path non-traditionally should be fearless to seek those who are willing to invest in, and help grow, their talent.

\section{Advice to Young Women}

For younger women in mathematics, my advice is to form your networks with intent, understanding that the formation of different kinds of networks-research, mentoring, and teaching - serve distinct purposes, but all can uniquely contribute to the advancement of your career, especially where they overlap. From networks blossom communities, and for me, these are communities of likeminded friends and mathematicians: Project NExTers, the AWM community, the IAS Women and Math Program, the Math Alliance, USTARS, the National Center for Faculty Diversity, SACNAS, etc.

\section{Comments on Women's History Month}

When returning from a conference and sharing with my daughter a narration of my travel, I find that the pictures of me and other women mathematicians-some the pioneers of a past generation and some the pioneers of a newer generation today-provide an empowering reminder of the preeminent tradition of women as actualizers of mathematics. It is a contemporary history in which we may all take pride.

The best homage to Women's History Month is to simply stop and think (at your next conference, take a moment to pause and examine who is represented), ask questions (inquire of conference organizers whether they have childcare funds available-or will with their next grant), become aware (of programs like EDGE and MSRI-Up, for which a simple recommendation to a young female student can be transformative), learn from the voices of women at all stages (a graduate student or a faculty member may co-organize a panel on the intersectionality of gender, math, and diversity at JMM or within your own institution), connect (check in with new female graduate students and faculty), and support good causes and people that do the same.

Photo Credit

Photo of Rosemary Guzman courtesy of Rosemary Guzman. 


\section{Tara S. Holm}

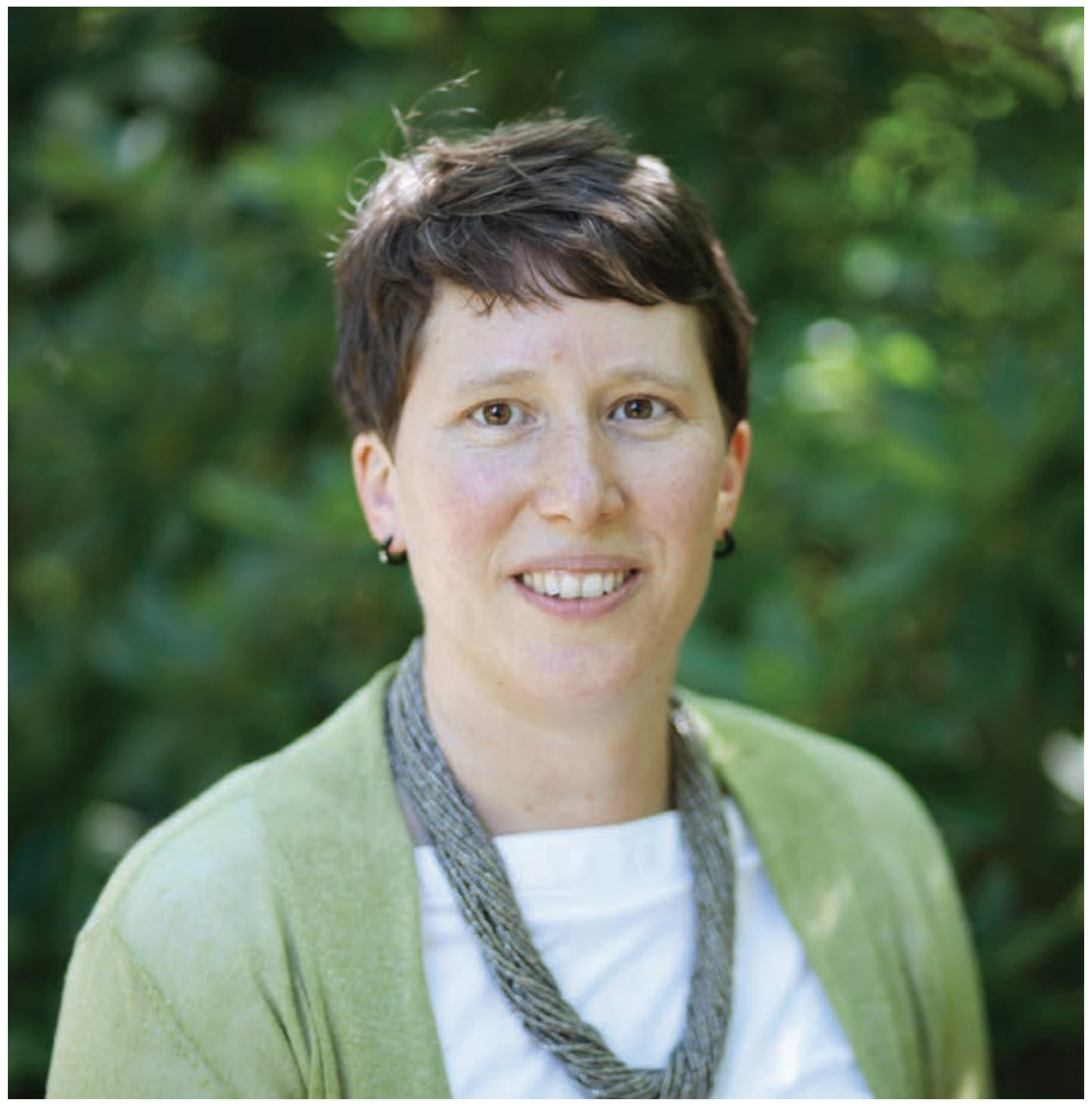


WOMEN'S

HISTORY

MONTH

\section{Synopsis of Research}

Tara S. Holm studies questions that originate in symplectic geometry but whose answers often involve methods from and have applications to algebraic geometry, algebraic topology, and combinatorics. Her principal focus is on group actions and quotients in symplectic geometry. Most recently she has made a foray into the developing area of quantitative symplectic geometry, analyzing the surprising new connections between symplectic geometry and number theory that arise when studying how one symplectic manifold can fit inside another. For embeddings of ellipsoids into toric surfaces, the question boils down to proving that a certain sum of two functions always has a positive output.

Holm has published over two dozen papers with nearly two dozen collaborators from half a dozen countries. She has advised two $\mathrm{PhD}$ students with more in the pipeline. Holm also has a deep passion for effective communication and undergraduate education. She envisions a world where all undergraduate students learn to recognize the beauty and power of mathematics.

\section{Biography}

Tara S. Holm is professor of mathematics at Cornell University. She earned her undergraduate degree at Dartmouth College and her PhD at MIT. She was an NSF postdoctoral research fellow at UC Berkeley and had been a faculty member at the University of Connecticut before arriving at Cornell. Holm has played leadership roles nationally with the American Mathematical Society; the Association for Women in Mathematics; Transforming Post-Secondary Education in Mathematics (TPSEMath.org); and Pro Mathematica Arte, the non-profit corporation that runs study-abroad programs for North American mathematics students in Budapest. She gives invited lectures around the world, including an AMS-MAA Invited Address at MathFest. Her research has been supported by grants from the National Science Foundation and the Simons Foundation. She is a Fellow of the American Mathematical Society and a 2013 Simons Fellow in Mathematics. At Cornell, she has been honored with a 2016 Mathematics Department Teaching Award and a 2017 Cornell Cook Award for improving the climate for women at Cornell. In addition to mathematics, she enjoys gardening, cooking with her family, and exploring the Finger Lakes.

\section{Advice to Young Women}

To young women entering the field, she would advise:

- Find collaborators, especially ones who are close enough to your field so that you can talk but far enough that they will teach you some new mathematics.

- Assume good intentions on the part of others. This helps smooth over most misunderstandings and may even turn adversaries into allies.

- Spend as much money as you can afford on the aspects of life that bring you the least joy (for Holm, that's laundry and house cleaning!). The time-for-money tradeoff is always worth it.

\section{Comments on Women's History Month}

On the occasion of Women's History Month, I have deep gratitude for the many senior women mathematicians who have made it easier for the younger generations to find their niche in the field. I have had the good fortune of many female role models and mentors whose encouragement carried me through some of the tougher moments of my career. I feel very lucky to have found a supportive network of collaborators and a job in an incredibly friendly and collegial department.

\section{Photo Credit}

Photo of Tara S. Holm by Melissa Totman. 
Olga Holtz

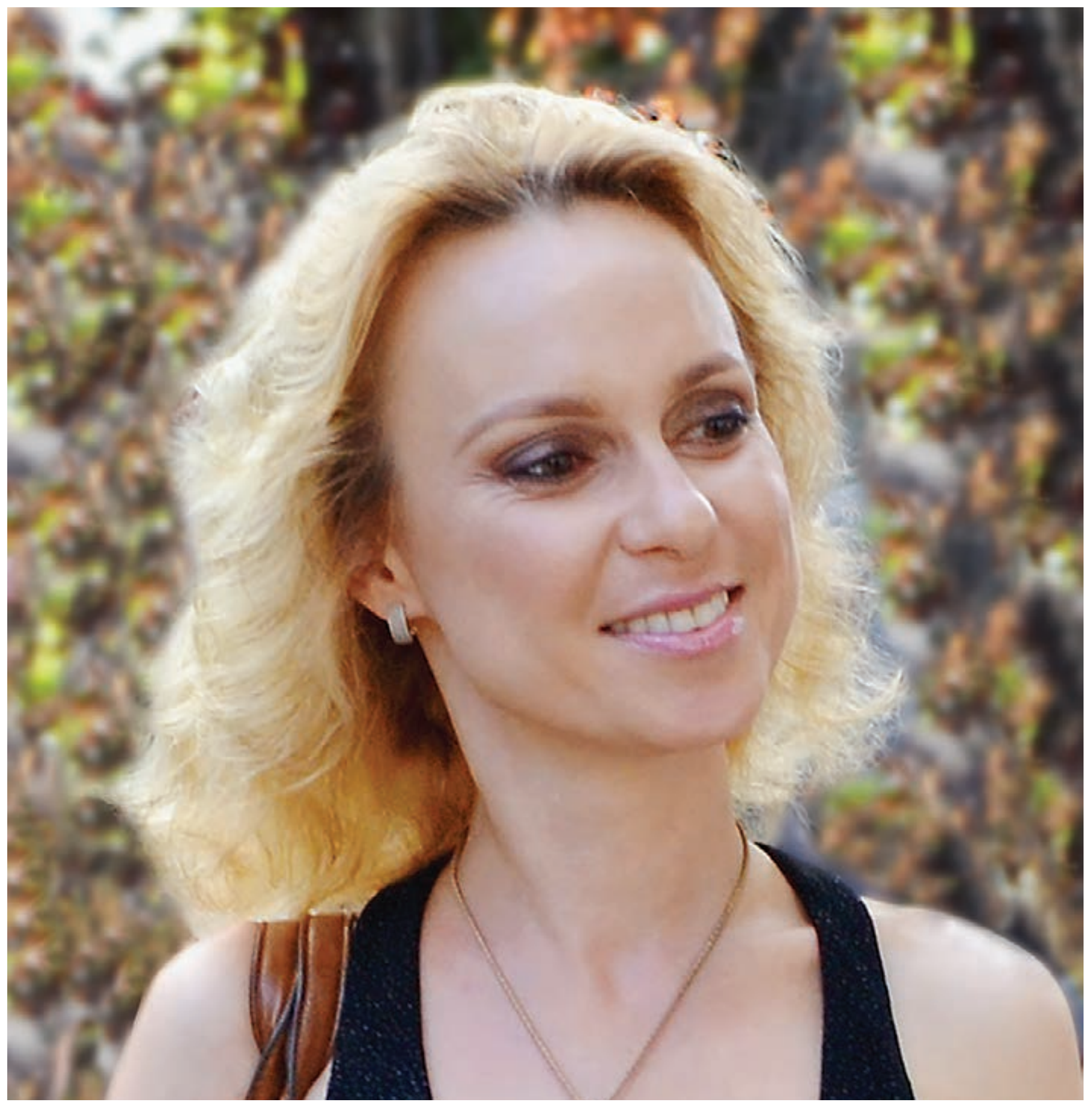


WOMEN'S

\section{HISTORY}

MONTH

\section{Synopsis of Research}

Olga Holtz's research interests include numerical analysis, parallel computing, complexity of algorithms, classical analysis, matrix and operator theory, approximation theory, orthogonal polynomials, commutative algebra, and enumerative combinatorics. Her main research contributions include solutions to several open problems in matrix theory, development of zonotopal algebra, building a framework for communication complexity of algorithms, and novel fast and stable parallel computation methods. In the future she hopes to complete a monograph on the Laguerre-Pólya class, a fascinating class of entire functions that appear in classical analysis, number theory, combinatorics, and statistical physics.

\section{Biography}

Olga Holtz received her diploma in applied mathematics from Southern Ural State University in Chelyabinsk, Russia, and her $\mathrm{PhD}$ in mathematics from the University of Wisconsin under the guidance of Hans Schneider.

She held a postdoctorate research position at the computer science department of the University of Wisconsin-Madison, a Humboldt Fellowship at the Institute of Mathematics of Technical University Berlin, and a Morrey assistant and an associate professorship at the Department of Mathematics of the University of California Berkeley.

Currently, Holtz is a professor of mathematics at the University of California Berkeley and a visiting professor of applied mathematics at Technical University Berlin and Berlin Mathematical School.

She has received a Sofja Kovalevskaja award, a European Mathematical Society Prize, an ERC Starting Grant, two von Neumann Fellowships at the Institute for Advanced Study, and an AMS Fellowship.

Holtz is also an award-winning screenwriter and film director.

\section{Advice to Young Women}

Dare to take risks in your career.

\section{Photo Credit}

Photo of Olga Holtz by Hamid Shafiezadeh. 


\section{Fern Y. Hunt}

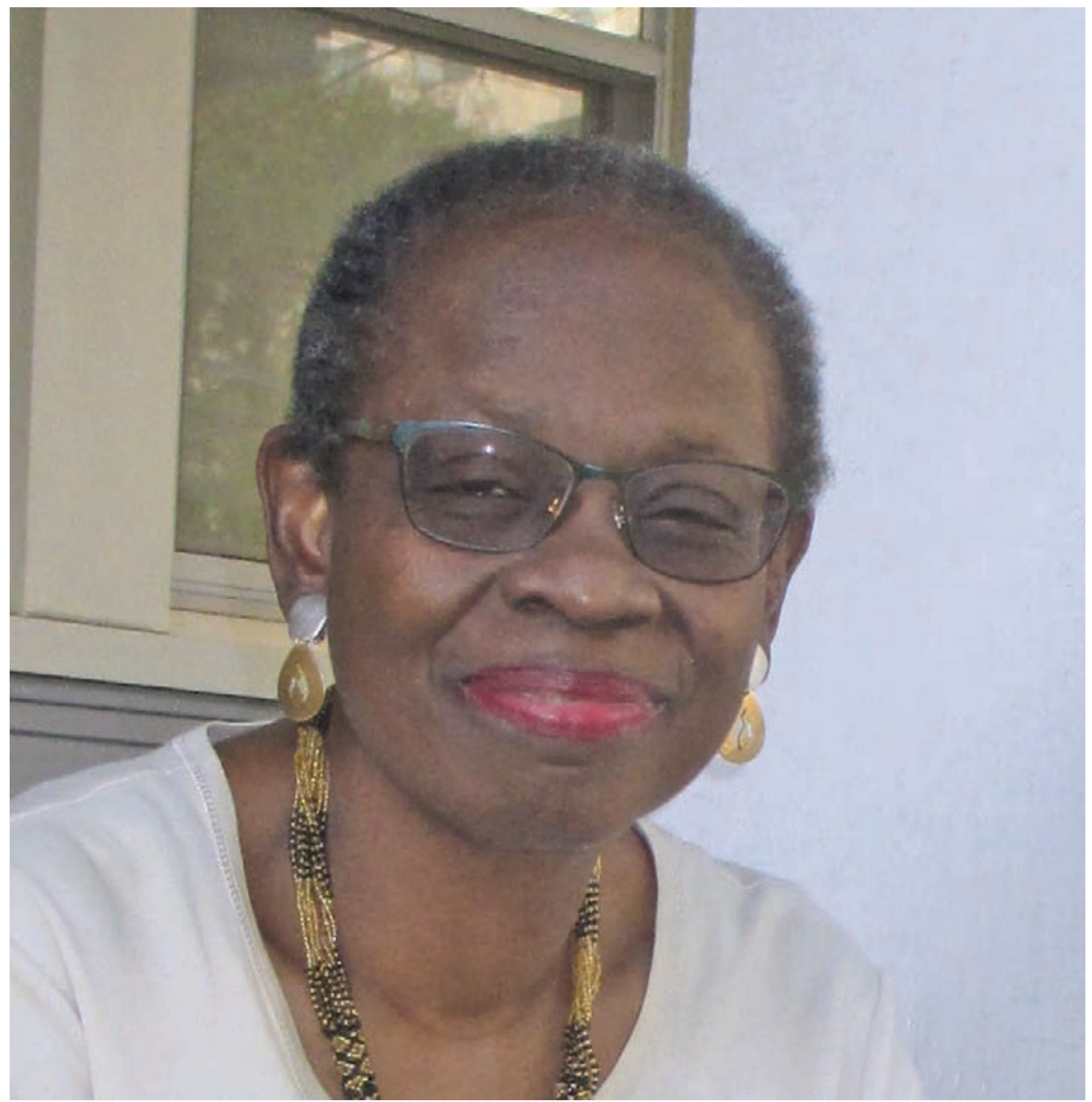


WOMEN'S

HISTORY

MONTH

\section{Synopsis of Research}

At NYU's Courant Institute, Fern Y. Hunt received a graduate education that blended pure and applied mathematics. Thus it was easier to consider working on problems that contributed meaningful insights into real-world problems while discovering interesting new mathematics. The result was a hybrid career of government and university involvement. Two examples illustrate what government research is like and how it might differ from what happens in an academic department. While at the Laboratory of Mathematical Biology at the National Institutes of Health, Hunt read an internal newsletter that reported the work of NIH researchers Loretta Leive and Robert Goldman. They studied the molecular chains that comprise the outer coating of gram negative bacteria. The coatings consist of chains of carbohydrate molecules of varying lengths that at once affect the degree of virulence of infection and play an important role in helping bacteria evade the immune systems of their hosts. Hunt met with them and after some eager initial discussion, a collaboration began. Using a simple Markov chain model of chain synthesis, they were able to offer a simple explanation for the data patterns Leive and Goldman observed based on a preference for the synthesis of certain chain lengths. This preference persisted even in mutant bacteria that had decreased capacity to produce single chain units.

The second example had an unusual beginning. Out of curiosity, Hunt attended what turned out to be an excellent lecture on clustering in random sequences by a senior (non-mathematician) scientist from the Glidden Paint company. There she met Jonathan Martin, NIST engineer and head of a group that studied degradation of painted and coated surfaces. Sometime later Hunt had a lunchtime chat with then division colleague Holly Rushmeier (now a professor of computer science at Yale University) about computer graphic rendering. That discussion led to a collaboration with other NIST scientists and university researchers on a project that demonstrated that radiometrically accurate but visually realistic computer-based renderings of appearance aspects of coated surfaces could be produced. This work was a proof-of-concept of what Hunt first thought was rather a quirky vision of Martin'sthat the standards governing the appearance of coated surfaces devised by committees of human industry and government experts could be enhanced or even replaced by computers that pass the Turing test, playing a visual "Imitation Game."

Hunt has also conducted research on the discrete approximation of dynamical systems and applications of Markov chains. More information on her research can be found in MathSciNet ${ }^{\circledR}$ or in the Web of Science database (under "FY Hunt").

\section{Biography}

Fern Y. Hunt is a New York City native. She graduated from Bryn Mawr College with a BA degree in mathematics and from the Courant Institute of Mathematical Sciences with a PhD in 1978. Later that year Hunt joined the faculty of Howard University's mathematics department, where she received an NSF Career Award, other NSF grants, Howard University research grants, and an Association for Women in Mathematics travel grant. In 1991, Hunt took a full-time position at the National Institute of Standards and Technology. In 1999, Hunt received the Arthur S. Flemming Award for outstanding federal service in science. Hunt has also appeared in the modern Leonardos exhibit at the Chicago Museum of Science and Industry since 2006. She has served on several committees, notably the NSF Committee of Visitors 2016, the organizing committee of the Infinite Possibilities Conference 2014-2015, the executive committee for AWM in 2002-2006, and the first Association for Women in Mathematics Olga Taussky Todd Award Committee in 2006. Hunt has also served on the Bryn Mawr College Board of Trustees and been an emerita member since 2009.

\section{Advice to Young Women}

If you are a recent $\mathrm{PhD}$ or you have just begun research in a new subfield, I would recommend attending as many research conferences as time and money allow. If this is not practicable, make use of online resources such as the arXiv and MathSciNet and read the blogs of outstanding mathematicians in your area. If you have written several papers on a particular topic, organize a special session at an annual conference and invite speakers working in your field. This is a good way to stay abreast of what is happening and identify possible collaborators. Like many mathematicians I am quite introverted; but as a woman of color, I often had to operate way out of my comfort zone. You cannot be isolated and be successful.

\section{Photo Credit}

Photo of Fern Y. Hunt courtesy of Fern Y. Hunt. 
Trachette L. Jackson

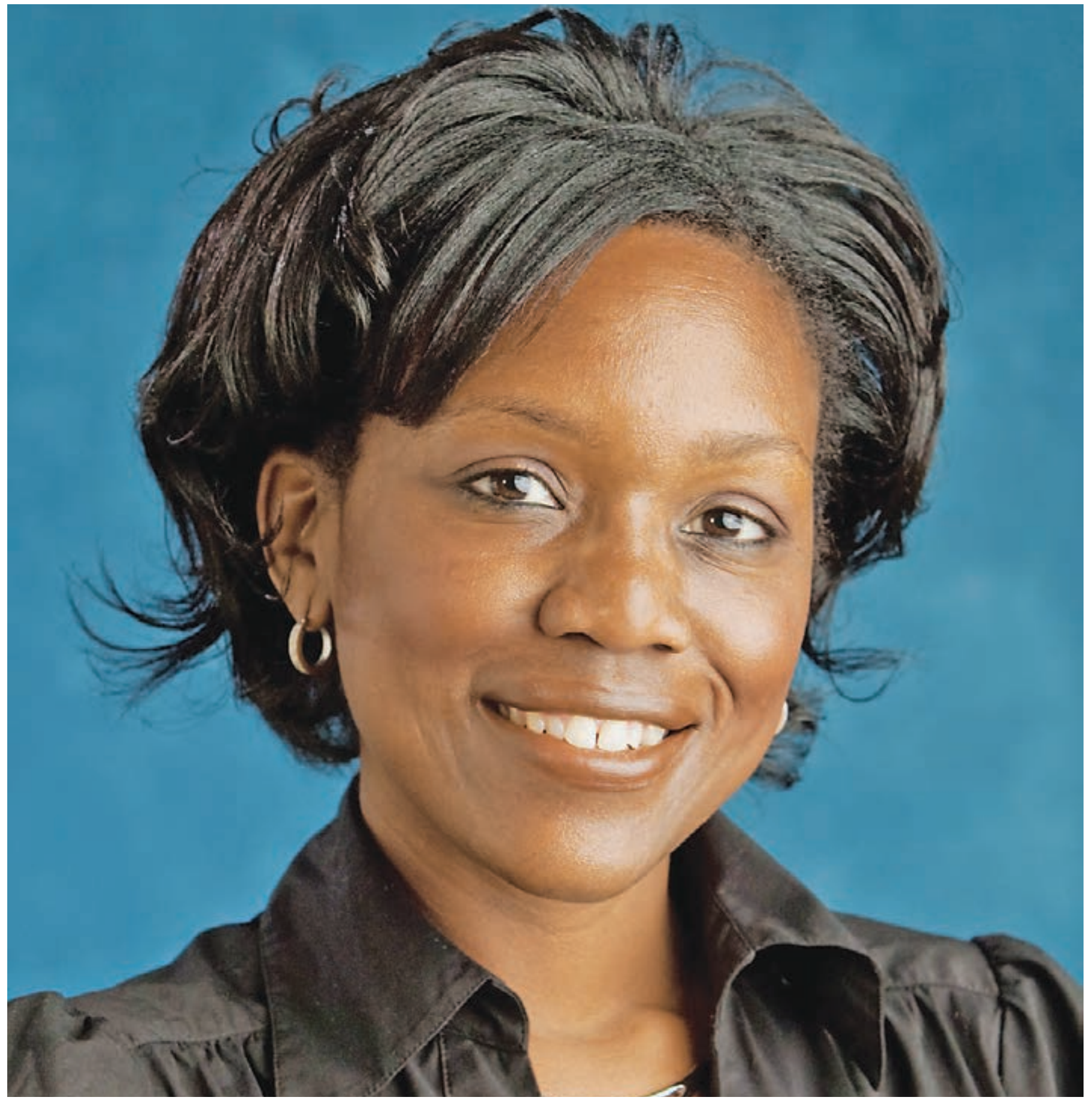


WOMEN'S

HISTORY

MONTH

\section{Synopsis of Research}

Trachette L. Jackson's research lies within the overarching field of mathematical biology, which can be characterized by the use of sophisticated mathematical, statistical, and computational modeling techniques in order to facilitate a deep understanding of biology, for human benefit and the mitigation of human harm. Within mathematical biology she specializes in computational cancer research or mathematical oncology. It is an exciting time to work in this interdisciplinary field. Even TIME $^{\circledR}$ Magazine (April 2013) agrees that "a team-based, cross disciplinary approach to cancer research is upending tradition and delivering results faster." Mathematical and computational modeling approaches have been applied to every aspect of tumor growth, from mutation acquisition and tumorigenesis to metastasis and treatment response. Jackson's research focuses on developing mathematical approaches that are able to address critical questions associated with vascular tumor progression and targeted therapeutics.

\section{Biography}

Trachette L. Jackson earned her PhD in applied mathematics in 1998 from the University of Washington under the direction of James D. Murray, one of the founding leaders in the field of mathematical biology. She conducted postdoctoral research at the Institute for Mathematics and its Applications and at Duke University. She is currently full professor of mathematics at the University of Michigan. Jackson is an award-winning educator and scholar whose research in mathematical oncology has received international attention. In 2003, she became the second African American woman to receive the prestigious Alfred P. Sloan Research Award in Mathematics; in 2005 she received the James S. McDonnell 21st Century Scientist Award; in 2008 Diverse Magazine honored her as one of the year's Emerging Scholars. In 2010 she received the Blackwell-Tapia Prize, which recognizes a mathematician who has contributed significantly to research and who has contributed in significant ways to addressing the problem of underrepresentation of minorities in math.

Jackson's commitment to theoretical and computational cancer research is evidenced by her joint effort with Sophia Merajver to spearhead a Quantitative Oncology subsection in the authoritative journal Cancer Research, for which she now serves as senior editor. Jackson has built her career on collaborative research and educational activities that cut across traditional disciplinary boundaries and envisions that this type of research will eventually change the face of cancer research.

In order to address the national challenge of educating and training a diverse scientific workforce capable of unifying the fields of mathematics and the natural sciences, Jackson developed and directs the Applied and Interdisciplinary Mathematics Bridge to the PhD program at the University of Michigan. The long-term goal of the Bridge program is to prepare the next generation of under-repre- sented minority scholars to combine a deep knowledge of applied science with the mathematical, computational, and physical sophistication needed to address the increasingly complex problems on the horizon and to become leaders in the international scientific community.

\section{Advice to Young Women}

Be confident in your abilities, and don't let anyone dissuade you from pursuing your passion. Find a group of like-minded peers and a more senior mentor who can provide you with guidance and support.

\section{Photo Credit}

Photo of Trachette L. Jackson courtesy of Trachette L. Jackson. 


\section{Dusa McDuff}

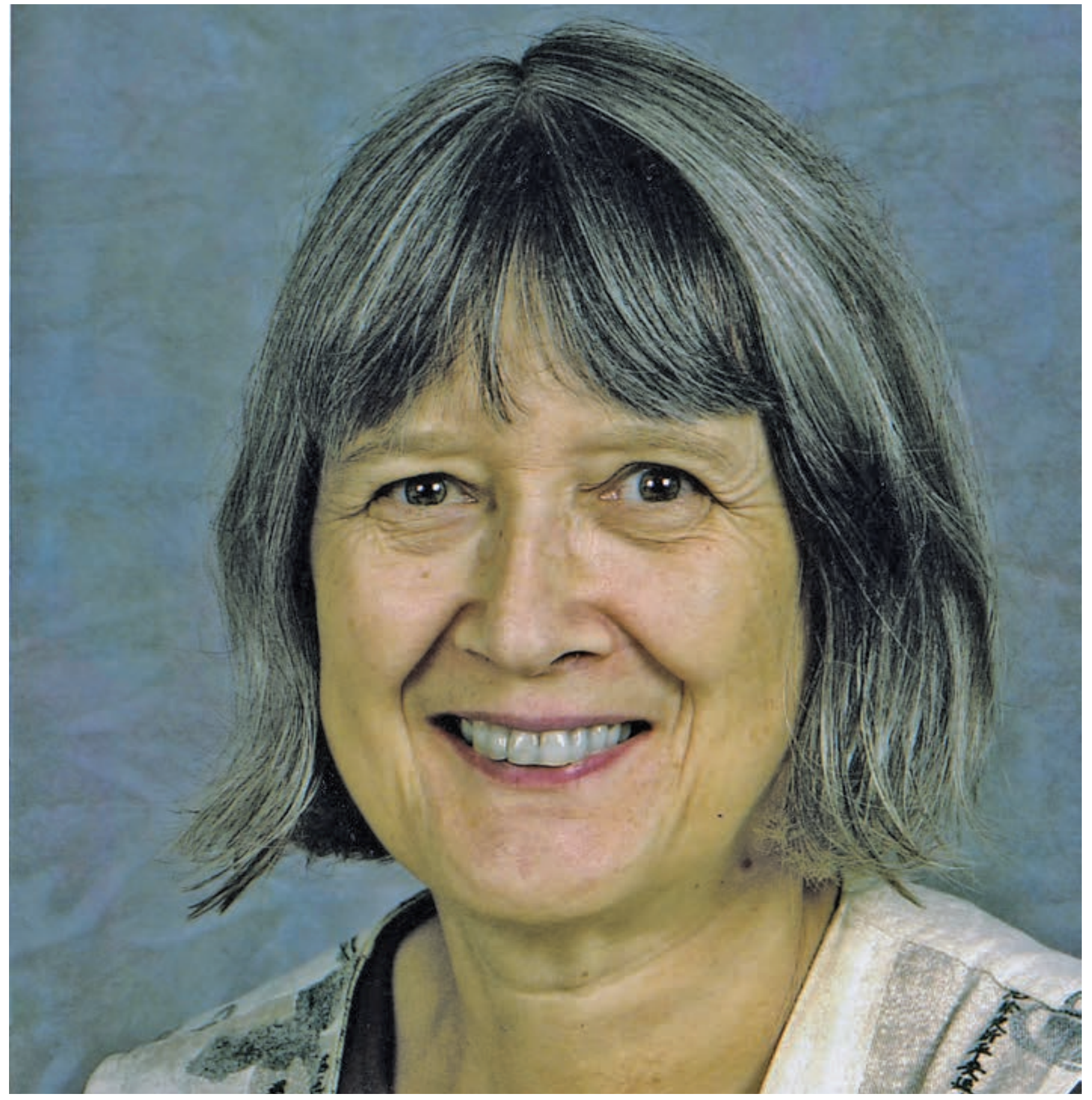




\section{WOMEN'S}

\section{HISTORY}

MONTH

\section{Synopsis of Research}

Dusa McDuff started her career in functional analysis, but after studying for six months with Gel'fand in Moscow, moved into algebraic topology. After completing what was essentially a second $\mathrm{PhD}$ with Graeme Segal, McDuff became interested in understanding the connections between the classifying spaces for foliations and diffeomorphisms, which gradually led her to study the group of symplectic diffeomorphisms. At that time, in the beginning and mid1980s, symplectic geometry was revitalized by several new insights, particularly by Gromov's introduction of J-holomorphic curves, and McDuff has stayed in that area of mathematics ever since. She used Gromov's theory to understand the properties of the symplectic blow up and blow-down construction (a variant of the construction in complex geometry) and to classify the simplest symplectic 4-manifolds, namely the rational and ruled manifolds. With Lalonde, McDuff spent many years trying to understand how to deform symplectic balls in dimension 4 and higher in order to explain the relation between ball embeddings and so-called displacement energy (which is a dynamic concept). More recently, McDuff has spent much time, both on her own and with Felix Schlenk and other collaborators, figuring out how to embed symplectic ellipsoids into each other and undertook a joint project with Katrin Wehrheim to clarify various foundational issues in the field of symplectic topology. McDuff has also written two textbooks with Dietmar Salamon.

\section{Biography}

I grew up in Edinburgh, Scotland, just after the end of the Second World War in an academic English family. I went to a girls' school and studied the cello at the wonderful Waddell School of Music. However, I found mathematics more compelling than cello playing and decided at an early age to become a mathematician, an academic career being the only kind of career that was valued in our house. I stayed in Edinburgh for my undergraduate work, going to Cambridge for my PhD. After two post-doc years in Cambridge, I was a lecturer in York and then Warwick, spent a transformative year at MIT in 1974-5, and went to Stony Brook University in 1978. Since 2007 I have been Helen Lyttle Kimmel '41 Professor of Mathematics at Barnard College. I was elected a Fellow of the Royal Society in 1994 and a member of the National Academy of Sciences in 1999. I was awarded the AMS Satter Prize in 1991 and (with Salamon) a Steele Prize in 2017.

\section{Advice to Young Women}

Although mathematics is often thought of as a product of the inspiration and brilliance of individuals, it could not exist without a framework that is sustained by the broader community. It is important to find your way in this community. The first step is probably to find some like-minded people (both fellow students and more senior mathematicians) with whom you can do mathematics and feel validated as a mathematician.

\section{Comments on Women's History Month}

Though the situation is much better than it was, women's contributions and potential are still greatly undervalued, both by themselves and by others. This special month provides more visibility for a variety of women with different approaches and contributions to the world of mathematics.

\section{Photo Credit}

Photo of Dusa McDuff courtesy of Dusa McDuff. 


\section{Sophie Morel}

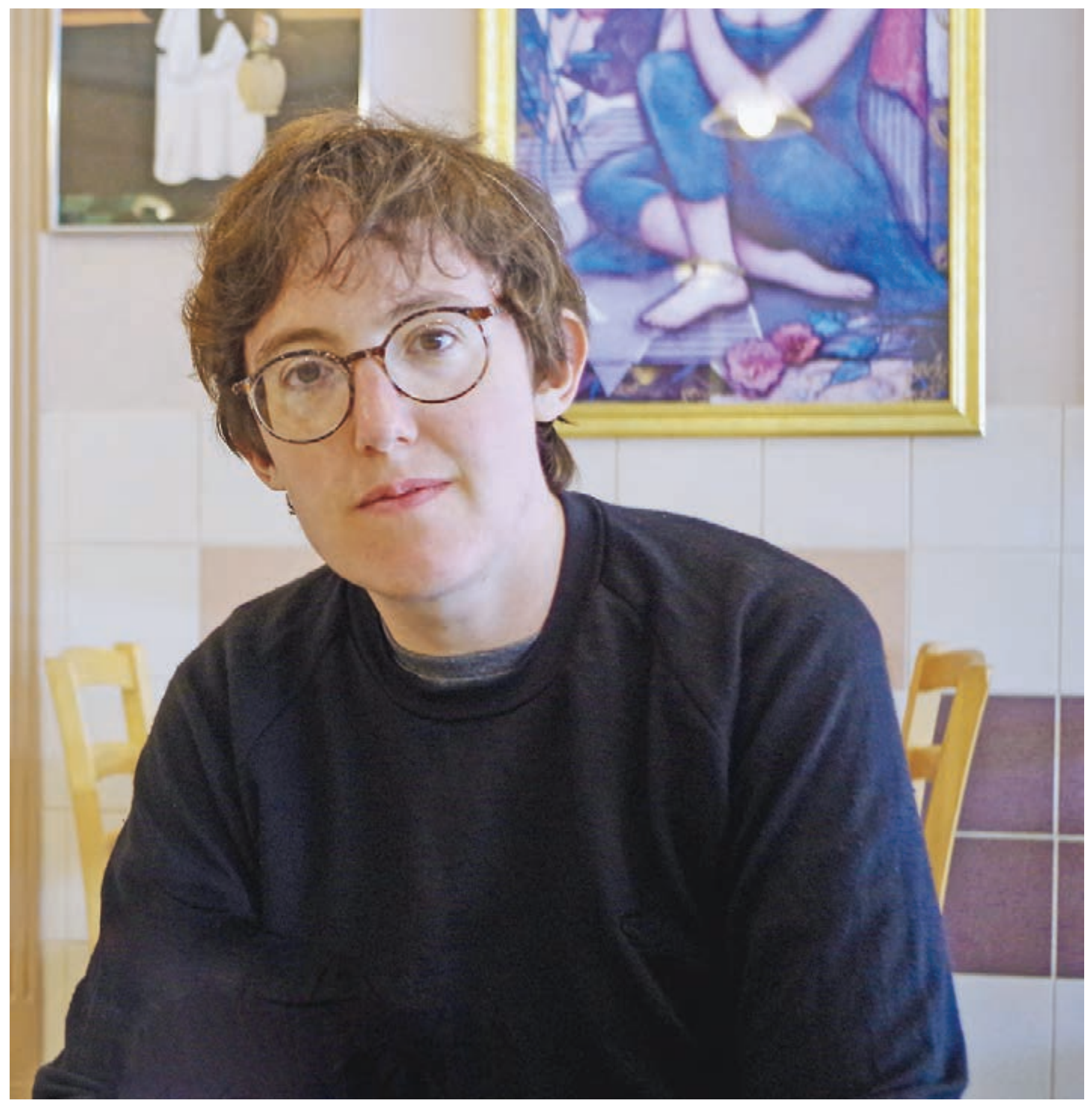




\section{WOMEN'S}

\section{HISTORY}

MONTH

\section{Synopsis of Research}

Sophie Morel's main interest of study is Shimura varieties, more broadly, the arithmetic Langlands program. She is also interested in motives, the geometric Langlands program, and the derived aspects of the Langlands program. She is currently studying automorphic representations appearing in the cohomology of moduli stacks of shtuka, and trying to understand derived deformation rings. Moduli stacks of shtuka, originally due to Drinfeld, play the role of Shimura varieties for the Langlands program over function fields, but without all the restrictions that come with Shimura varieties-so they are much more powerful.

Morel discovered a new way to calculate intersection cohomology and the intersection complex of a stratified scheme, which involves truncations by weights instead of cohomological degree. Here weights refer to Frobenius weights as in the Weil conjectures. (The truncation by cohomological degree formula is due to Deligne.) This way of calculating the intersection complex is an algebraic analogue of a more topological construction due to Goresky, Harder, and MacPherson called "weighted cohomology."

\section{Biography}

Sophie Morel studied at École Normale Supérieure in Paris and defended her PhD in December 2005 at the Université Paris-Sud under the supervision of Gérard Laumon. She was a Clay Research Fellow from 2006 to 2011, and joined the Harvard University mathematics department in 2009 as professor of mathematics. Morel is the first tenured woman in mathematics at Harvard. She joined the Princeton University mathematics department in 2012. She gave an invited talk at the 2010 International Congress of Mathematicians in Hyderabad, India, was awarded one of the prestigious European Mathematical Society Prizes in 2012, and received an Aisenstadt chair at CRM in Montréal in 2015. Morel has been a member of the Institute for Advanced Study in Princeton in 2006-2009, 2010-2011, and 2012-2013.

\section{Advice to Young Women}

My advice for young women is ignore people who try to put you down and just do your thing. Don't feel pressured to represent all female mathematicians. Also, as you go up the mathematical ladder of life, be sure to encourage people who are more junior than you.

\section{Photo Credit}

Photo of Sophie Morel courtesy of Theodore Ehrenborg. 


\section{Andrea Nahmod}

Ceustructions Invaniduce.

bbs mea sue (Bourgain)

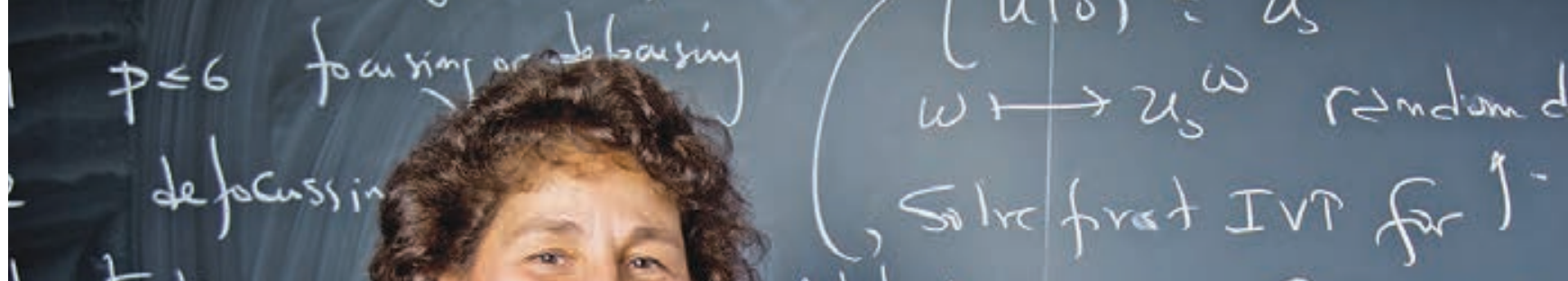

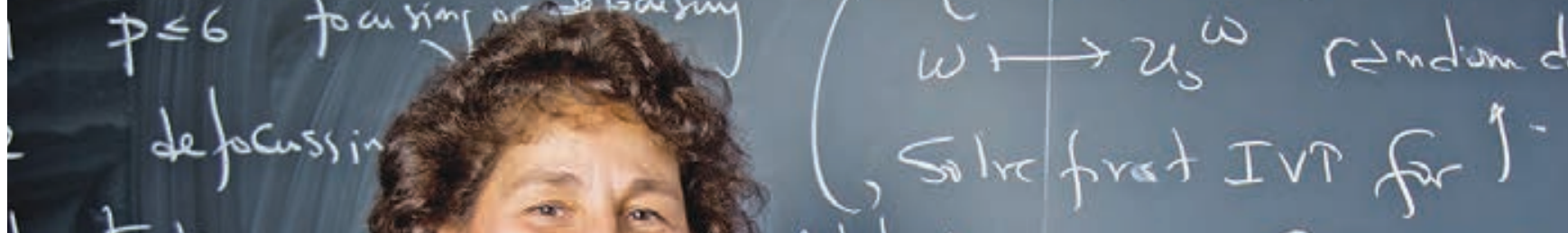

cunsturetin $d \geqslant 3$.

Dow do te

Normal

We

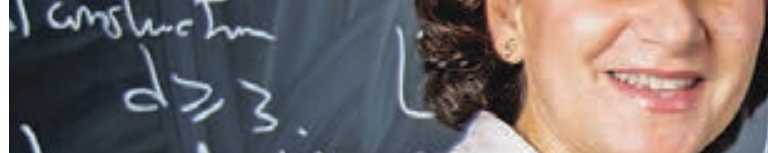

2) get Iwp $\rightarrow u=S(t) u_{0}^{\omega}+z$

$i \partial_{t} z+\Delta z=N\left(S(t) u_{1}^{\omega}+z\right)$

(a) $z(0)=0$

Littewad Bay de comp $\rightarrow$ fre untera chin strichartt $\rightarrow$ dispension

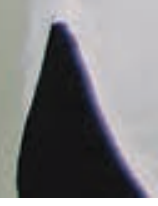




\section{WOMEN'S}

\section{HISTORY}

MONTH

\section{Synopsis of Research}

Andrea Nahmod is professor of mathematics at the University of Massachusetts Amherst. Broadly speaking, her research interests are in two interrelated fields: nonlinear Fourier and harmonic analysis, and the theory of partial differential equations modeling wave propagation phenomena. These are two areas that intimately relate to each other by way of decompositions, frequency interactions analysis, and nonlinear estimates. Nahmod contributed to the understanding of bilinear singular pseudo-differential operators naturally arising in analysis and PDEs and to the wave-packet analysis techniques successfully used in their study. She has also worked on questions aimed at understanding the dynamics of nonlinear waves arising in geometry, ferromagnetism, and gauge field theories.

Over the past ten years Nahmod has been working to analyze and gain a more quantitative understanding of the effect of randomness in the dynamical evolution of PDEs in various regimes, following Bourgain's seminal ideas in the 1990s, integrating tools from probability into her research. There are a myriad of fascinating questions to be explored in exciting and developing new directions at the forefront of nonlinear PDEs. Nahmod likes approaching a problem in new ways, to move the problem forward in a different fashion.

\section{Biography}

My interest in mathematics started at a young age. My fondest memories include sitting in my mother's kitchen as an elementary school child doing my math homework.

My undergraduate thesis advisor and mentor in Argentina was Cora Sadosky. She taught me not only harmonic analysis but also what mathematical research is about. She also helped me to pursue my $\mathrm{PhD}$ in the US.

I received my $\mathrm{PhD}$ degree in mathematics from Yale University under the supervision of Ronald R. Coifman. He taught me a great deal of mathematics, and I am deeply indebted to him for the generosity of his ideas and his contagious enthusiasm and love of mathematics. I have tried to pay these forward with my own students. I also learned a great deal of mathematics from Karen Uhlenbeck whom I was lucky to start collaborating with while I was at UT Austin in the mid-1990s. I have found my stays at the Institute for Advanced Study in Princeton as a member in 1997-1998 and in 2003-2004 to be very fruitful; similarly, my stay as the Sargent-Faull Fellow at Harvard's Radcliffe Institute for Advanced Study in 2009-2010. In 2013-2014 I received a Simons Fellowship and in fall 2015 I was a Simons Professor at MSRI in Berkeley, where I also co-organized a jumbo program. At UMass Amherst, I was named the 2015-2016 Spotlight Scholar and was a recipient of the Award for Outstanding Accomplishments in Research and Creative Activity in 2016. I have been a Fellow of the AMS since 2015.

\section{Advice to Young Women}

If I had to give advice to young women in regards to developing one's own research program, I would say: have a broad mathematical culture, follow your intuition, keep a long view about research, and love what you do.

\section{Comments on Women's History Month}

Despite so much hard-fought progress for equal rights for women by so many before my generation and in my generation, I still imagine a more equitable workplace for women-one where our biases, implicit and otherwise, fade away. Equal pay for equal work is right and it is fair, and it is past time that we as a society demand it and work together to achieve it-all of us, because women are also mothers, sisters, spouses, and daughters, and they all deserve as much respect.

\section{Photo Credit}

Photo of Andrea Nahmod courtesy of John Solem. 


\section{Lillian Pierce}

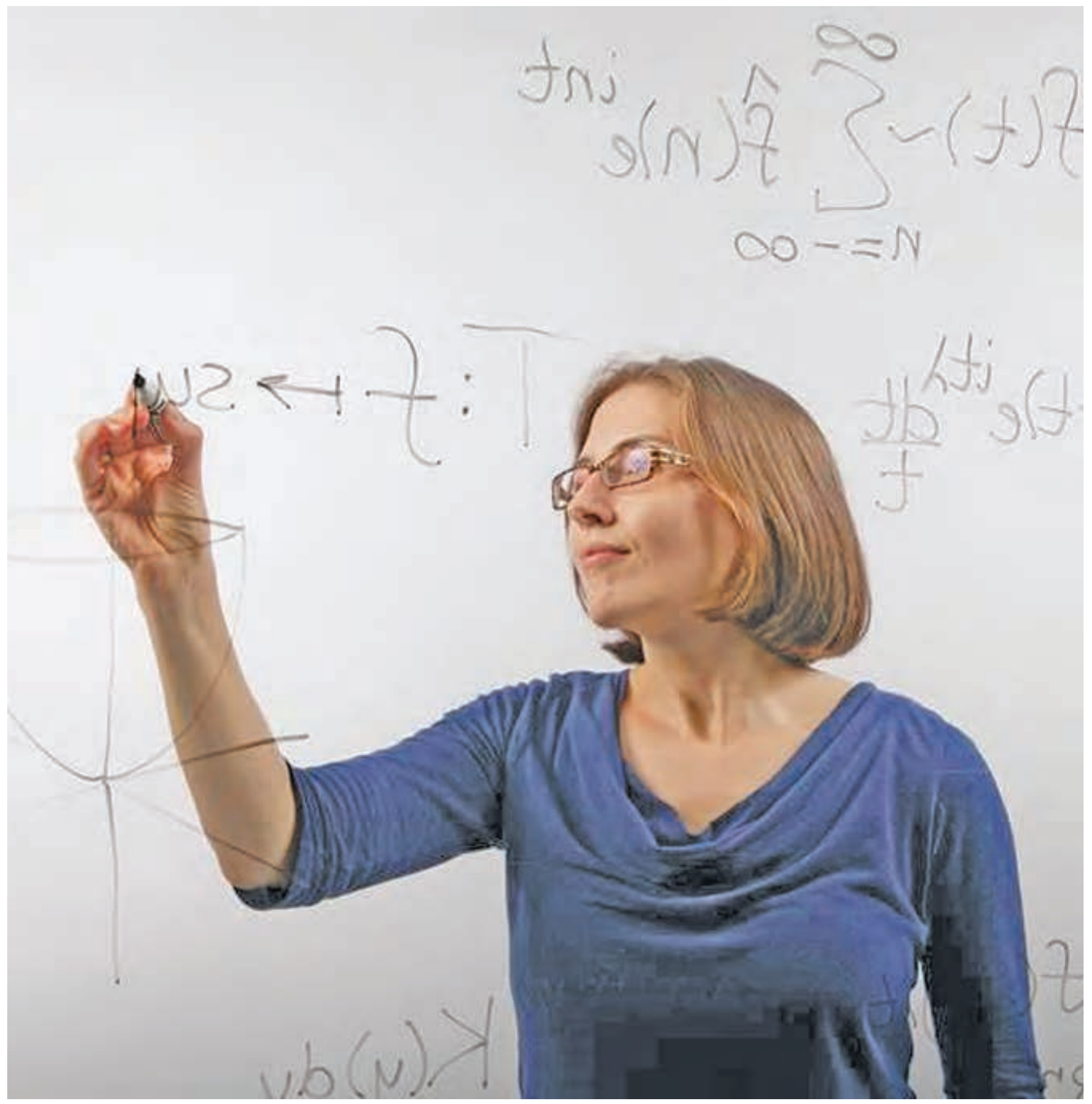




\section{WOMEN'S}

\section{HISTORY}

MONTH

\section{Synopsis of Research}

Lillian Pierce works in the areas of analytic number theory and harmonic analysis. Many of her results have been on $p$-torsion in class groups of number fields, where she has made progress toward conjectured strong upper bounds by developing diverse methods involving sieves, counts for number fields, and zero-density results for automorphic $L$-functions. She has also worked on the circle method, both in the classical context of counting solutions to systems of Diophantine equations and in applications to discrete operators in harmonic analysis. One of her core interests is in bounding character sums and oscillatory integrals, which play a key role in both fields. In particular, her interest in oscillatory integrals has led to work on a new class of Carleson operators that exhibits Radon-type behavior. Pierce's long-term interests are in clarifying and building on deep connections between analysis and number theory.

\section{Biography}

Lillian Pierce grew up in a small town in California and was primarily educated at home, with a significant focus on violin performance. As an undergraduate at Princeton, she completed the pre-medical curriculum but meanwhile majored in math, because its clarity and precision had seemed appealing since childhood. The intensive curriculum and the experience of independent work with encouraging mentors made it clear that a career as an academic mathematician looked like a perfect fit. She then completed graduate work at Oxford and Princeton, followed by postdocs at the IAS and Oxford, and after a year as a Bonn Junior Fellow took up a faculty position at Duke University. Pierce was a Rhodes Scholar and Marie Curie Fellow. She has recently been awarded the AWM-Sadosky Research Prize in Analysis, an NSF CAREER grant, and a von Neumann Fellowship at the Institute for Advanced Study. Having benefited tremendously from the generosity of many mentors, Pierce works consciously to build an inclusive atmosphere for 21 st-century mathematics.

\section{Advice to Young Women}

I find it important to remember what I love about math. In fact, it's very simple. I like to understand things, down to the last detail. There are many other aspects to a career in mathematics, but when I need to, I know to shut all of that out and just return to this basic enjoyment in understanding.

\section{Comments on Women's History Month}

Role models matter. I was shocked when my son, at the age of three, blurted out, "Boys can't do math." Well, he was right in that at that time in our family the girls were the ones talking about math. But it was time to bring him into the club right away. For my own role models, I continually add to a stockpile of photographs and articles about women throughout history who startle me with their determination, insights, goals, and struggles. I know that my mother couldn't have gone to the undergraduate institution I attended because it didn't accept women at that time. Yet when I showed up, I was welcomed with open arms, gained a terrific education, and graduated as valedictorian of my class. In the next generation's turn, I hope we will make new, wonderful, flexible opportunities available for all our children.

\section{Photo Credit}

Photo of Lillian Pierce courtesy of Duke Photography. 
Jill C. Pipher

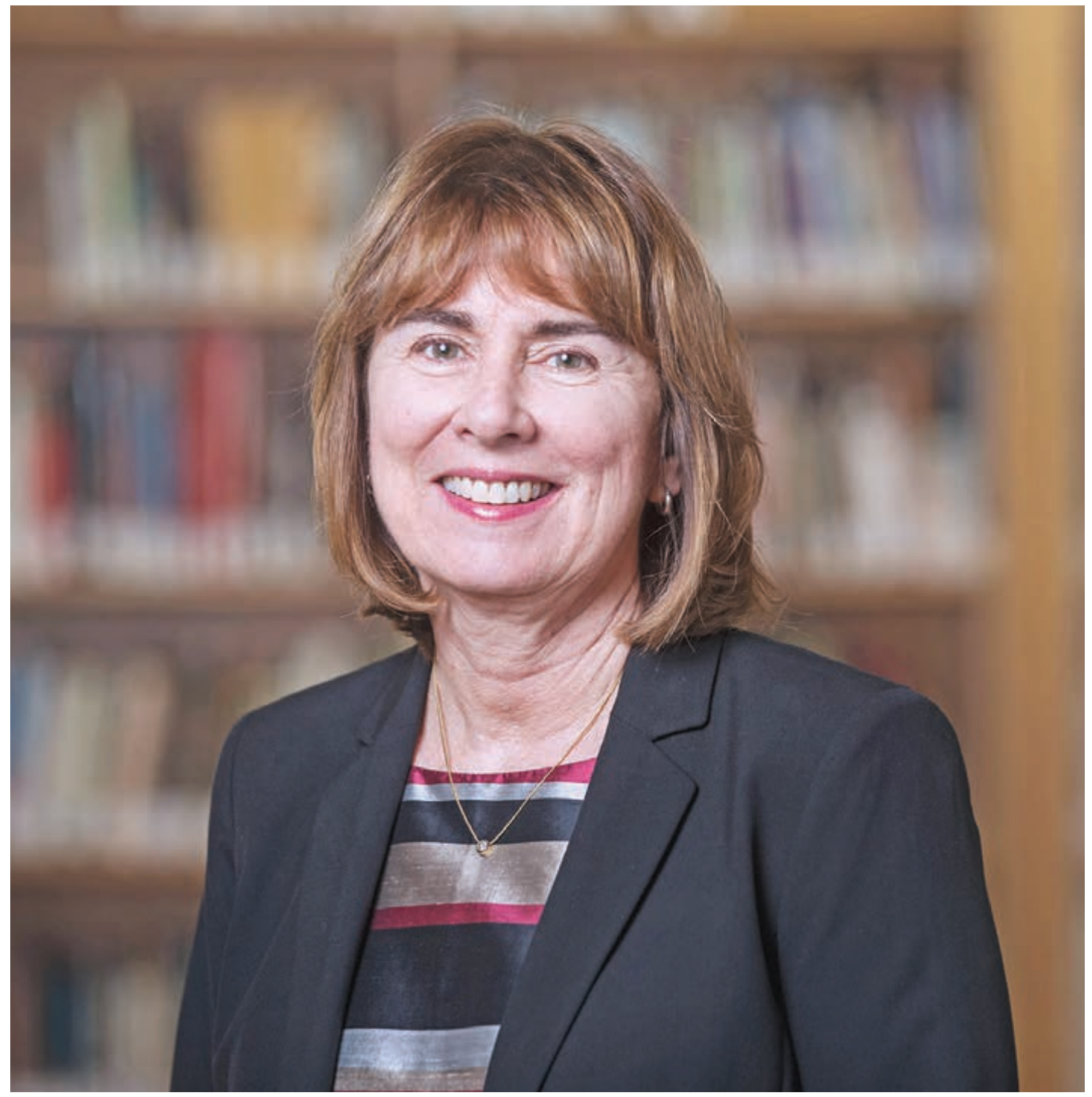




\section{WOMEN'S}

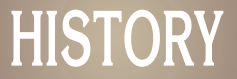

MONTH

\section{Synopsis of Research}

Jill C. Pipher's primary areas of research are harmonic analysis and non-smooth linear elliptic and parabolic boundary value problems. She has also worked on lattice-based cryptography, particularly the NTRU public key encryption system and related algorithms. Her work in harmonic analysis has focused on singular integral operators, the theory of weights, and especially the associated multi-parameter theory. In elliptic and parabolic PDEs, she has contributed to key developments in the theory of divergence form equations with non-smooth coefficients, of perturbations of operators, of higher order operators like the bi-harmonic equation, and of non-symmetric equations, where she has helped to create new tools for solving boundary value problems that yield precise connections between the smoothness of the coefficients and the regularity of the solutions.

\section{Biography}

Jill C. Pipher is vice president for research at Brown University and Elisha Benjamin Andrews Professor of Mathematics. In addition to her administrative responsibilities, she is currently co-teaching a freshman class in mathematics, advising graduate students, and serving on committees of several professional societies. She was the founding director of the Institute for Computational and Experimental Research in Mathematics (ICERM). She received her PhD from UCLA in 1985, spent five years at the University of Chicago, and came to Brown in 1990 as associate professor. She was a co-founder of NTRU Cryptosystems, Inc., now part of Security Innovation, Inc., and jointly holds four patents for NTRU algorithms. She has been awarded an NSF Postdoctoral Fellowship, an NSF Presidential Young Investigator Award, and an Alfred P. Sloan Foundation Fellowship, and she is a Fellow of the American Mathematical Society. She served as president of the Association for Women in Mathematics from 2011-2013, and was a National Women's History Month 2013 Honoree. In 2015, she was elected to the American Academy of Arts and Sciences. She is now president-elect of the AMS.

\section{Advice to Young Women}

First, I think it is important to be flexible and open-minded about the variety of mathematical careers available. There are many types of jobs within academia, and many more without. I found that being open to different possibilities at critical career junctions in my life had a very positive effect on my sense of control over my future, boosting my confidence as well. Second, I strongly advise seeking, or even creating, opportunities to build professional networks and find mentorship. This is important for everyone at an early stage in their career, but especially for women and other members of under-represented groups.

\section{Comments on Women's History Month}

In 2013, I was honored to participate in a panel of distinguished Rhode Island women to discuss the importance of STEM education and skills, part of a celebration of National Women's History Month hosted by Senator Jack Reed. Every year, Senator Reed teams up with the Women's Fund of RI to celebrate the accomplishments and contributions of women. The 2013 theme was "Women Inspiring Innovation Through Imagination: Celebrating Women in Science, Technology, Engineering, and Mathematics." Like other panel discussions that bring together women in STEM fields, the discussion was honest, sometimes moving, and always fascinating. I am grateful that Women's History Month is a catalyst for these important events that help us reflect on where we've been, where we are now, and how we can effect change in the future.

\section{Photo Credit}

Photo of Jill C. Pipher courtesy of Brown University. 
Emily Rieh|

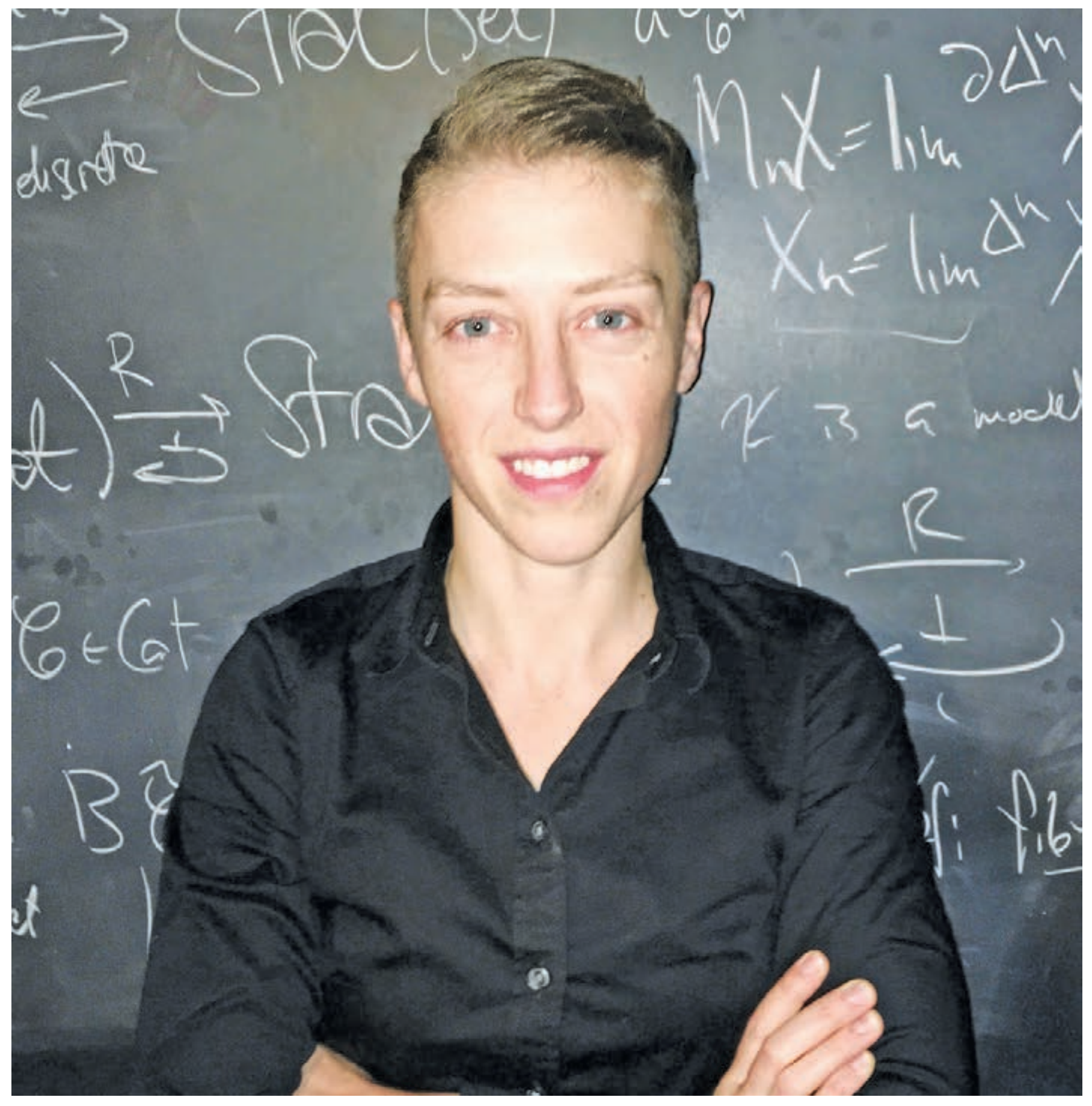


WOMEN'S

HISTORY

MONTH

\section{Synopsis of Research}

A category provides a template for a mathematical theory supplying nouns, to represent those mathematical objects, and verbs, to represent the transformations between them. But as the objects mathematicians study increase in complexity, a more sophisticated linguistic palate is required, including adjectives, adverbs, conjunctions, and so forth. Such objects live most naturally in weak infinite-dimensional categories, commonly nicknamed $\infty$-categories. Pioneering work of André Joyal and Jacob Lurie to extend ordinary 1-category theory to $\infty$-categories is "analytic" in the sense that it is developed using the combinatorics of a particularly convenient model of a weak infinite-dimensional category. Emily Riehl's joint project with Dominic Verity redevelops this theory "synthetically," with proofs that hold in any $\infty$-cosmos, their axiomatization of the "universe" in which $\infty$-categories live as objects. Their $\infty$-cosmological approach both simplifies definitions and proofs of certain key components from the analytic theory and also generalizes them without change to other well-behaved models of infinite-dimensional categories. In future work, Riehl plans to write a textbook exposing these developments, originally described in a series of seven research papers, and also plans to apply similar techniques to develop the theory of higher-dimensional analogues of $\infty$-categories.

\section{Biography}

I specialize in category theory, particularly as related to homotopy theory, and have been assistant professor of mathematics at Johns Hopkins University since 2015. Prior to this, I was an undergraduate at Harvard University, completed Part III of the Maths Tripos at Cambridge, earned my $\mathrm{PhD}$ in 2011 from the University of Chicago, and then spent four years at Harvard as an NSF and Benjamin Peirce Postdoctoral Fellow. I am the author of two books, Categorical Homotopy Theory (Cambridge 2014) and Category Theory in Context (Dover 2016), both of which are freely available online; a co-author of 20 published research articles; and have written many other expository works with various degrees of polish. I am the founder of the Kan Extension Seminar, an online graduate reading course in category theory with participating students from around the globe, and a co-host of The n-Category Café. I serve as an editor for Journal of Homotopy and Related Structures; Homology, Homotopy, and Applications; and Cahiers de Topologie et Géométrie Différentielle Catégoriques. I am a member of the AMS Mathematics Research Community Advisory Board and chair of the AMS Web Editorial Group. I have been awarded an NSF grant and a CAREER award to support my work. I have also been recognized for excellence in teaching at both Johns Hopkins and at Harvard. I am currently advising somewhere between two and four $\mathrm{PhD}$ students and mentoring one postdoctoral fellow, and I will be co-organizing an MSRI semester on Higher Categories and Categorification, which will take place in 2020.

\section{Advice to Young Women}

Regarding advice, I would have appreciated being reassured that it's ultimately up to me how I want to spend my time. I particularly enjoy giving talks and am unusually enthusiastic about expository writing, so I say yes to most speaking engagements and take on a lot of extracurricular writing projects. This means less time for research and other things, but it also makes me happier, so feels like a win overall. I think the fetishization of research above all else is really damaging to both the self-confidence of members of our community and to the community as a whole, which requires superlative advisors, inspiring teachers, diligent referees, compassionate mentors, efficient organizers, and so on to function in a healthy way.

Photo Credit

Photo of Emily Riehl courtesy of Mona Merling. 
Karen E. Smith

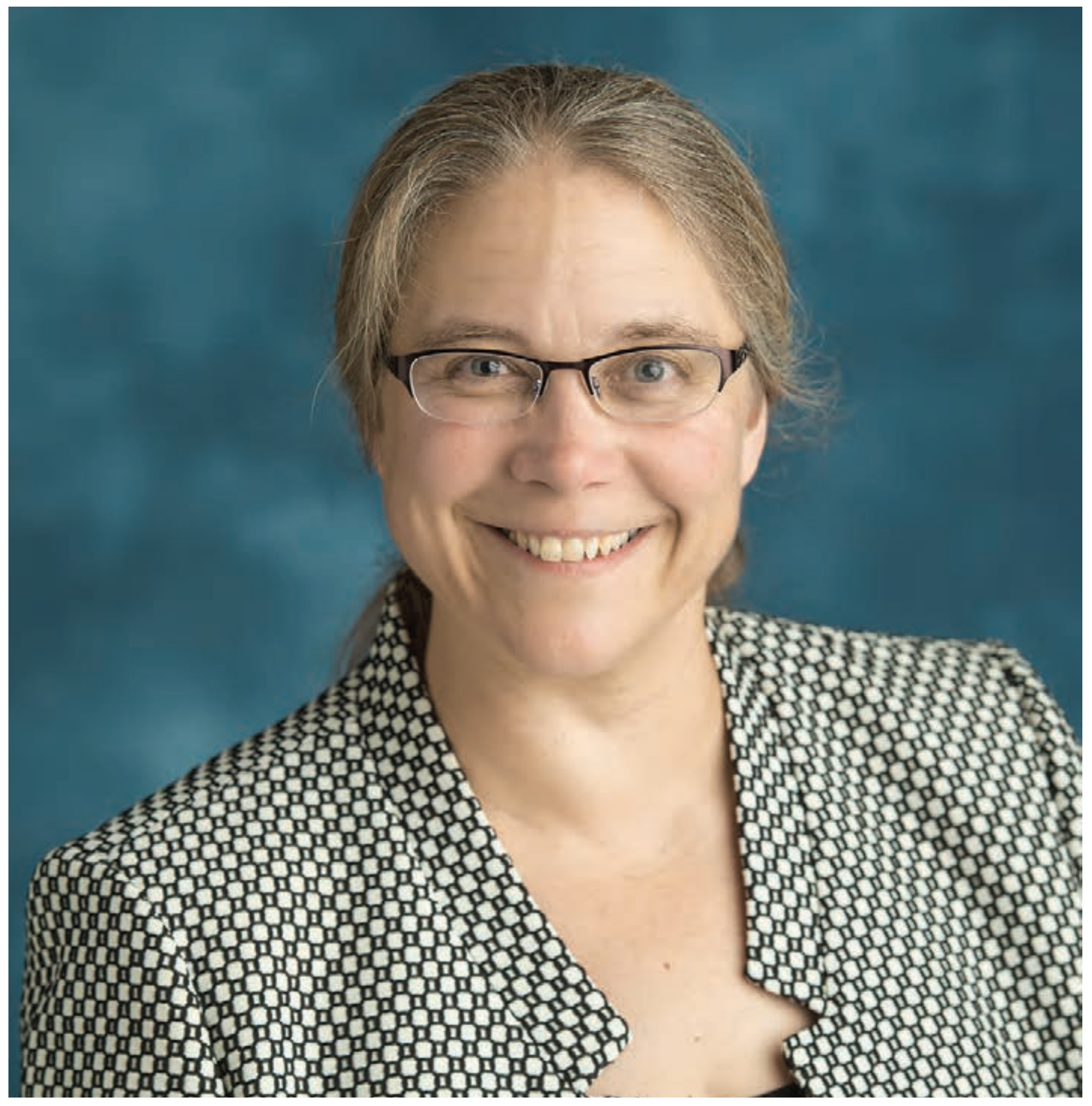


WOMEN'S

HISTORY

MONTH

\section{Synopsis of Research}

Karen E. Smith's research is in commutative algebra and algebraic geometry. She is known for using prime characteristic techniques in commutative algebra to solve problems in algebraic geometry and other subjects. For example, she has been a pioneer in understanding the singularities of varieties over finite fields, characterizing them by considering the Frobenius action on local cohomology modules. Her paper linking the multiplier ideal with the test ideal has been at the center of an industry connecting the singularities and tools of the minimal model program with singularities and tools in prime characteristic commutative algebra. With Robert Lazarsfeld and Lawrence Ein, Smith discovered a surprisingly tight relationship between symbolic and ordinary powers of ideal sheaves in smooth complex varieties, founding a major field of investigation. Jointly with Michel Van den Bergh, she developed a theory of differential operators in prime characteristic for strongly F-regular rings that spawned new singularity invariants such as the F-signature. She is especially proud of her success training over sixteen $\mathrm{PhD}$ students and about as many post-docs, many of whom are now powerful researchers in their own right.

\section{Biography}

Karen E. Smith was born and raised near the Jersey shore and never heard of graduate school until after graduating college. She was one of a small cohort of math majors at Princeton, and, thinking she was no good at math, accepted a high school teaching job upon graduation. While she loved high school teaching, she found herself discouraged by an extremely difficult job. Luckily, she ran into a former peer from Princeton who mentioned he was a $\mathrm{PhD}$ student in mathematics, and, in fact, getting paid to teach calculus to college freshman while deferring his student loans. That was enough for her to decide to apply to graduate school. She enjoyed her job as a Graduate Student Instructor at the University of Michigan, where she was surprised to discover she was quite well prepared for her graduate courses. She finished her $\mathrm{PhD}$ in commutative algebra with Mel Hochster in 1993, and accepted an NSF post-doctoral fellowship at Purdue University under the direction of Craig Huneke. As a post-doc, she began studying algebraic geometry, a process that accelerated when she moved to Boston to accept a Moore Instructorship at MIT. In Boston, she found many math friends and peer collaborators, laying the foundations of a successful research program aimed at using the Frobenius map in characteristic $p$ to prove theorems about singularities and vanishing of cohomology. Her work was recognized with the Satter Prize in 2001.

In 1997, Smith moved back to Ann Arbor with her husband Juha Heinonen, where they both accepted professorships. As a young professor, she birthed her first child, Sanelma, who travelled to many conferences as an infant, often with dad or grandma as babysitter. Indeed, because
Juha was so supportive and she had accumulated so many great ideas in Boston, the years after Sanelma was born were quite productive mathematically, even with a small child. Five years later, she accomplished what she still considers her most impressive feat: birthing twins Tapio and Helena and completing an amazing family.

Smith faced a major setback in 2007, when her husband Juha was taken by cancer. Her youngest were only three years old when he fell ill, so she has not been able to travel or work as much since then. Fortunately, the vibrant mathematical community in Ann Arbor has enabled her to continue her mathematical work. She loves working with post-docs and students, and loves teaching and mentoring at all levels.

She is currently associate chair of graduate studies at the University of Michigan and the faculty advisor for the local student chapter of AWM. She is also an important mentor for many of Michigan's African American math majors and has a special interest in helping and mentoring the growing number of undergraduates who transfer to UM from community colleges. Now remarried to another Finnish analyst, Kai Rajala, she is enjoying three teenagers at home and countless twenty-something students in her office, while trying to prove new theorems about rings of differential operators in characteristic $p$.

\section{Advice to Young Women}

Start where you are at; do not compare yourself with others. Learn the basics well- "exposure" to fancy stuff is fine too, as long as you also take the time to deeply understand the basics. Remember to have fun, with math and with life. Find places you thrive, mathematically and otherwise. Be bold seeking advice, but remember that not all advice is good. Above all else, marry a feminist.

\section{Comments on Women's History Month}

I still remember the thrill when, as a sophomore in Math 325-Professor Moore's abstract algebra course at Princeton-I was reading about the founder of modern algebra in Jacobson's textbook and saw the pronoun she. Emmy Noether. Probably until that point I would have said that I never felt constrained by gender, but wow. Everything was different after that in a way that is hard to explain to those privileged enough to never, consciously or unconsciously, question whether or not they belong. While it was a terrific feeling, I wish that tomorrow's daughters would be spared it. Maybe the Notices celebration of Women's History Month can play a tiny role in helping today's daughters see that they really do belong and, in fact, are needed.

Photo Credit

Photo of Karen E. Smith (c) Eric Bronson, Michigan Photography. 


\section{Gigliola Staffilani}

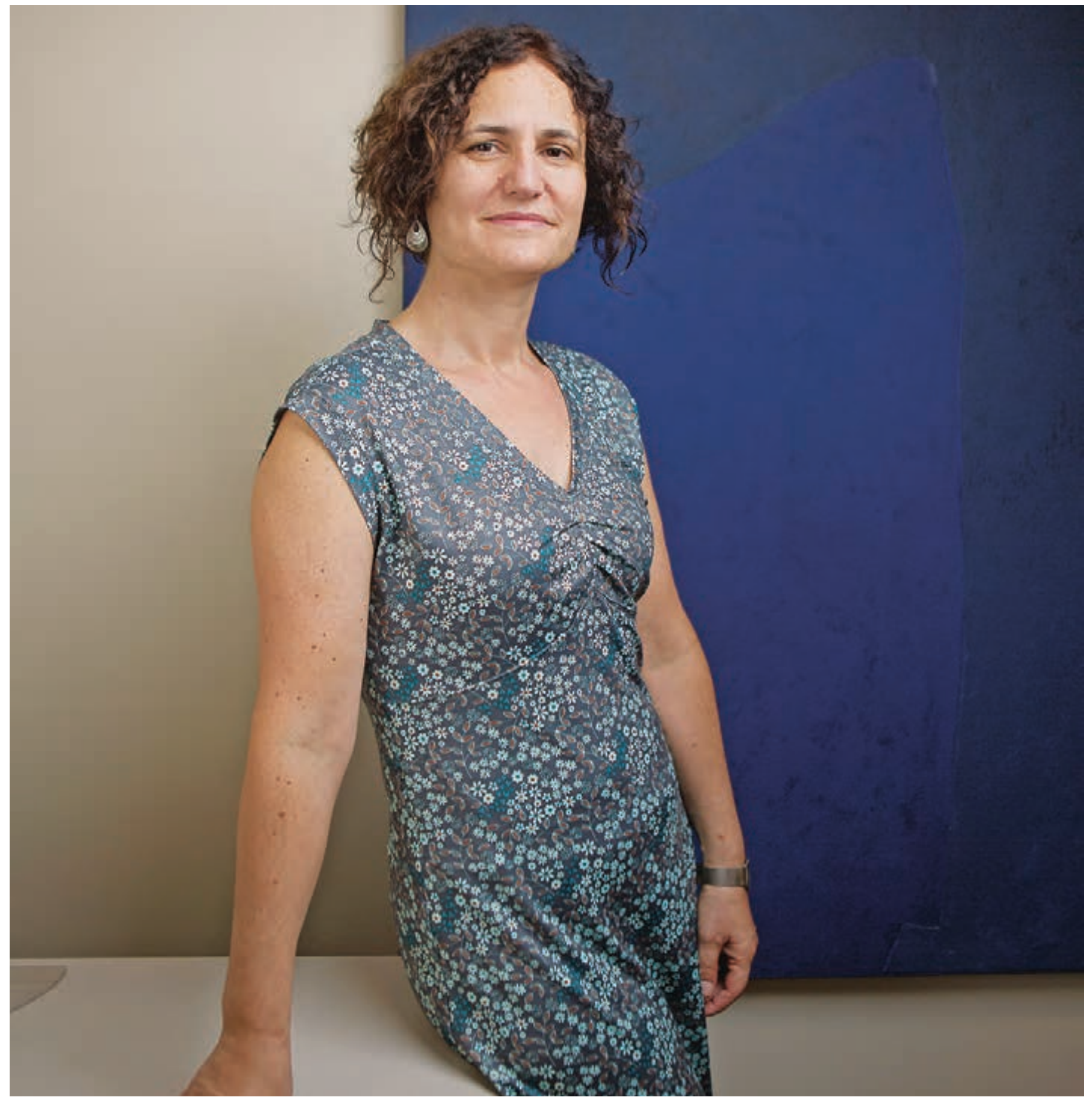


WOMEN'S

HISTORY

MONTH

\section{Synopsis of Research}

Gigliola Staffilani is interested in studying certain partial differential equations that model nonlinear wave phenomena. Often, because of nonlinearity of the problem, explicit solutions cannot be found. Hence her job is to be able to deduce certain properties of these solutions without knowing how they look. These properties include existence, uniqueness and stability of the solutions themselves, their long-time dynamics (including asymptotics), and their interactions. Staffilani has been enjoying this line of research for many reasons, but most of all because the tools used to attack the relevant questions come from different areas of mathematics: harmonic and Fourier analysis, analytic number theory, geometry, probability, and dynamical systems. In particular, in the last five years Staffilani has been introducing more and more probabilistic concepts in the work that she has done. Often it is not possible to say that every initial profile generates a wave solution, but we would like to prove it generically. Probability helps us in defining with rigor what "generically" means. The most enjoyable part of Staffilani's research career so far has been walking the path of investigation together with her collaborators, starting with her advisor Carlos Kenig and the I-team (Jim Colliander, Markus Keel, Hideo Takaoka, and Terry Tao) in the early years of her career. From her collaborators Staffilani learned an incredible amount of mathematics, and she shared with them several moments of frustration as well as of enthusiasm.

\section{Biography}

Gigliola Staffilani is the Abby Rockefeller Mauzé Professor of Mathematics at MIT. She received MS and PhD degrees from the University of Chicago in 1991 and 1995. Following a Szegö Assistant Professorship at Stanford, she had faculty appointments at Stanford, Princeton, and Brown before joining the MIT mathematics faculty in 2002. At Stanford, she received the Harold M. Bacon Memorial Teaching Award in 1997, and was given the Frederick E. Terman Award for young faculty in 1998. She was a Sloan fellow from 2000-2002. At MIT Staffilani served as co-chair of the Graduate Student Committee in Pure Mathematics from 2009-2013, and since 2015 has been the Faculty Diversity Officer. In 2013 she was elected member of the Massachusetts Academy of Science and a Fellow of the AMS, and in 2014 Fellow of the American Academy of Arts and Sciences. In 2017 she received a 2017 Guggenheim Fellowship and a 2017 Simons Fellowship in Mathematics. As a member of the department's edX group, Staffilani received the inaugural MITx Prize for Teaching and Learning in MOOCs by the MIT Office of Digital Learning. Gigliola has had six graduate students, including three current ones. She has also advised dozens of math majors at MIT.

\section{Advice to Young Women}

I recommend to anybody who wants to pursue research in mathematics to work with other mathematicians. The model of the lonely researcher in his ivory tower does not match with most of the mathematicians I know. This is a myth that definitely needs to be busted: it is dangerous and not encouraging.

\section{Comments on Women's History Month}

It is very important to remind people that there are still too few women in mathematics. Great efforts have been made in recent years to improve this number, but a lot more work has to be done. I hope that celebrating Women's History Month will at the same time recognize the achievements of many women mathematicians while inspiring young ones to dedicate their intellectual power to prove more new and powerful theorems.

\section{Photo Credit}

Photo of Gigliola Staffilani by Bryce Vickmark. 
Éva Tardos

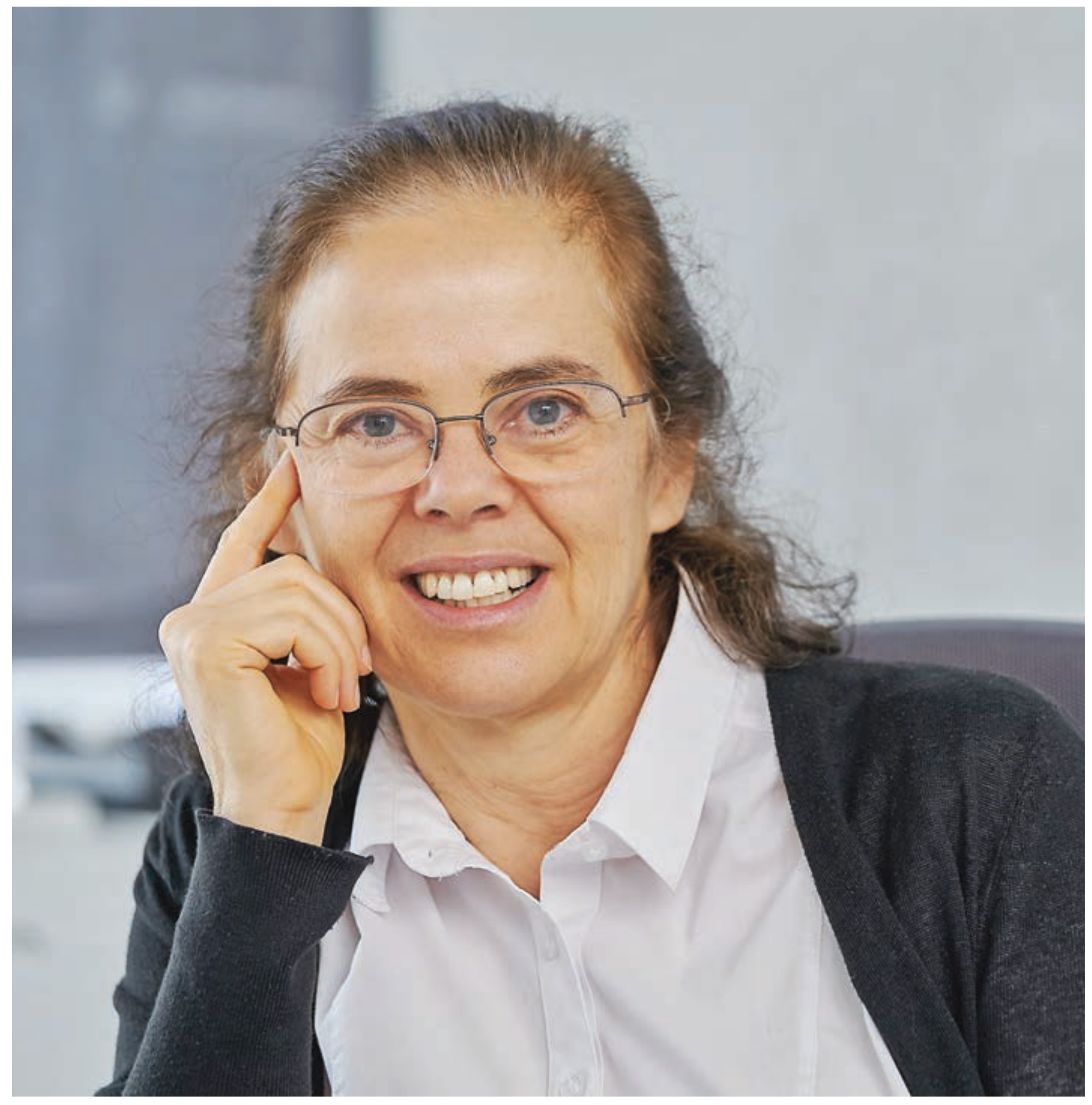


WOMEN'S

HISTORY

MONTH

\section{Synopsis of Research}

Éva Tardos's research interest is algorithms and algorithmic game theory. She is most known for her work on network-flow algorithms and quantifying the efficiency of selfish routing. For network-flow algorithms, she developed an efficient algorithm to find minimum-cost flow in a network in time that depends only on the size of the networks, independent of the magnitude of the costs. She also extended this result to a class of combinatorial linear programs. Extending it to all linear programming remains an important open problem in the field. For the last fifteen years her work has been focused at the interface of economics and the theory of computing, understanding how to design systems and algorithms for selfish users. An important example is traffic routing, car traffic or Internet traffic. Drivers or routers choose the path of the traffic to minimize delay, where the time to traverse an edge increases with congestion. The classical Braess paradox shows that this individual optimization may not lead to an overall optimal solution: deleting edges in the network can improve travel time for all users. Tardos's results offer bounds quantifying the resulting inefficiency. Similar analysis also offers insight on the quality of simple auction systems, such as eBay or advertisement auctions used by many platforms. In most of these applications both the system and the individual participants use machine learning to optimize the outcome. Tardos is currently extending her work to identify and understand good learning algorithms in such situations.

\section{Biography}

Éva Tardos is Jacob Gould Schurman Professor of Computer Science at Cornell University. She received her BA and $\mathrm{PhD}$ from Eötvös University in Budapest. She joined the faculty at Cornell in 1989 after a sequence of postdocs including time at Berkeley and MIT. At Cornell, she was computer science department chair from 2006-2010. She has been faculty advisor for the student group Women in Computing at Cornell since its founding, and is serving as the college's diversity lead. She has been elected to the National Academy of Engineering, the National Academy of Sciences, and the American Academy of Arts and Sciences. She is an external member of the Hungarian Academy of Sciences. She is the recipient of a number of fellowships and awards, including the Packard Fellowship, the Gödel Prize, the Dantzig Prize, the Fulkerson Prize, the ETACS prize, and the IEEE Technical Achievement Award. She was selected as the faculty of the year twice by computer science undergraduates. She is editor-in-chief of the Journal of the Association for Computing and has also served as editor of several other journals, including the SIAM Journal of Computing and Combinatorics. She was program committee chair for the 1996 ACM-SIAM Symposium on Discrete Algorithms, the 2005 IEEE Symposium on Foundations of Computer Science, and the 2013 ACM Conference on Economics and Computation.

\section{Advice to Young Women}

I have greatly enjoyed working on a wide range of problems during my career and would encourage young researchers to be open to exciting new opportunities in research, whenever they have the right basic tools to contribute.

\section{Comments on Women's History Month}

I'd like to recommend the one-minute GE YouTube video, "What If Millie Dresselhaus, Female Scientist, was Treated Like A Celebrity." 1

\section{Photo Credit}

Photo of Éva Tardos by Dave Burbank. 


\section{Chelsea Walton}

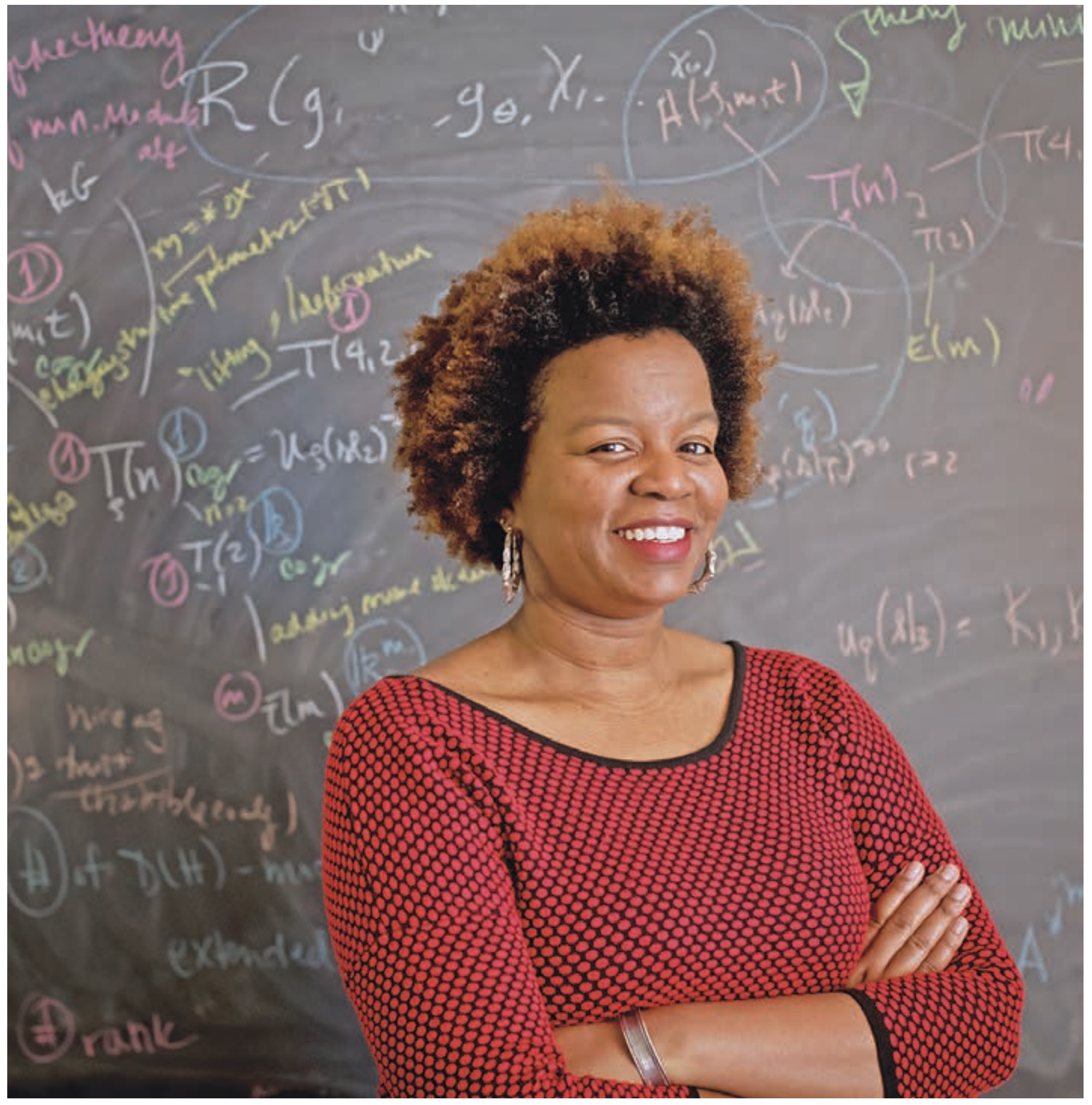




\section{WOMEN'S}

\section{HISTORY}

MONTH

\section{Synopsis of Research}

Chelsea Walton is assistant professor of mathematics at Temple University and will start a tenured position at the University of Illinois UrbanaChampaign in fall 2018. Walton's areas of research lie in noncommutative algebra, noncommutative algebraic geometry, quantum algebra, and representation theory. One of her main interests is (co)actions of Hopf algebras and quantum groups.

\section{Biography}

I was born and raised in Detroit, and I'm very proud of being from there. I attended Detroit public schools for my K-12 education, save a couple of years in elementary school. I was super lucky to be able to attend a middle school that had a STEM-oriented curriculum; this planted the seeds in me that doing math for a living would be my dream job. After high school, I enrolled at Michigan State University and University of Michigan for undergrad and graduate school, respectively. My first positions were as an NSF postdoc at University of Washington Seattle and as a Moore instructor at MIT.

If I had to name key lessons that I learned at each stage of my training and career, all would involve communicating math-writing, speaking, collaborating-more effectively. This is actually my favorite part of the job-sharing math. In fact, one way I decide if I'm going to work on a particular project is by imagining myself giving a talk (or, in my mind,"putting on a show") on the subject.

\section{Advice to Young Women}

I was asked to give some advice for young women in math here, but I find that it's tough to provide one-size-fits-all words of encouragement. People have very different needs. So, I highly recommend finding, valuing, and supporting your network of people, in math or not, who can selflessly give you words of encouragement. People who make you a better You. Pick your advisors, mentors, friends, and network carefully, as they will either inspire you or drain you. Choose the inspirers whenever you can, because the happier you are, the more math you will do!

\section{Comments on Women's History Month}

Thank you for including me, and I look forward to reading the other bios of current women in math in this issue and also in future issues of Notices. I'm honored and humbled to be a part of a group of women who could serve as role models for future generations of women and other groups of underrepresented mathematicians.

\section{Photo Credit}

Photo of Chelsea Walton courtesy of Ryan S. Brandenberg/Temple University. 


\section{Amie Wilkinson}

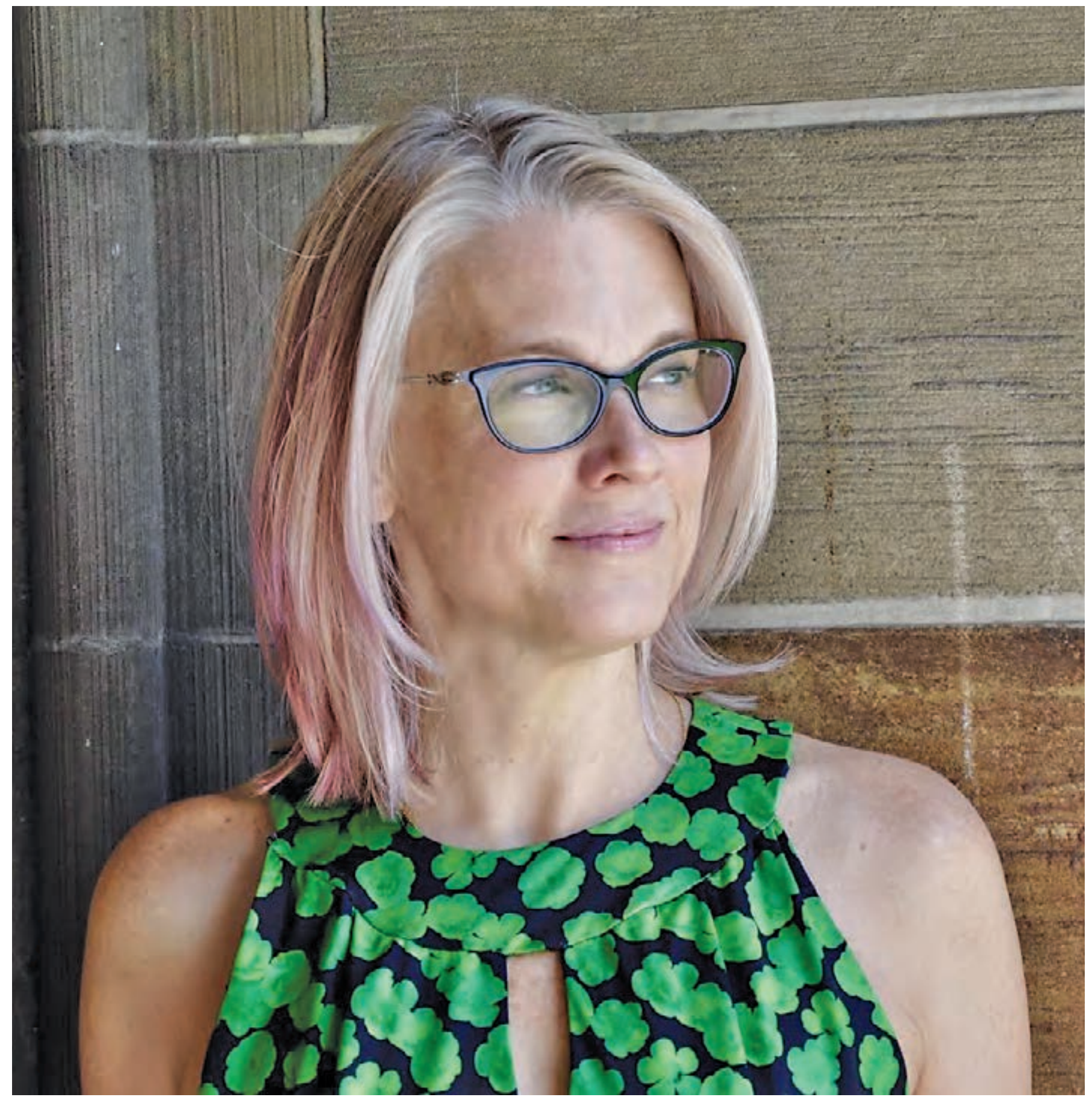




\section{WOMEN'S}

\section{HISTORY}

MONTH

\section{Synopsis of Research}

Amie Wilkinson studies dynamical systems-spaces in motion. Dynamics as a field was born in the late 19th century and grew out of attempts to describe the evolution of physical systems over time, both on large time scales (the stability of planetary motion) and tiny ones (the mixing of particles in an ideal gas). Wilkinson's research is concerned with the interplay between dynamical phenomena and other structures in pure mathematics-geometric, statistical, topological, and algebraic. Her contributions include establishing a general mechanism for stability of mixing (with Keith Burns); proving the $C^{1}$ version of a question of Smale: the generic diffeomorphism has no symmetries (with Christian Bonatti and Sylvain Crovisier); showing that the Weil-Petersson flows arising in Teichmüller theory are mixing (with Burns and Howard Masur); and establishing a version of Boltzmann's ergodic hypothesis for $C^{1}$ diffeomorphisms with positive entropy (with Avila and Crovisier).

\section{Biography}

I have always liked math, and I grew up in ideal circumstances to develop my interest, with supportive family and teachers. Off to an easy start, I still struggled along the way, nearly abandoning in college my plan to become a mathematician. This was due in part to a lack of female role models, but also due to the realization that I was far from the best math student at Harvard. Taking a year off after college to work, I stopped looking at other people and took a long, hard look at math itself. I missed it. I applied to graduate school and chose Berkeley, where I was joined by 100 other people in my class. That suited me fine.

In grad school, I discovered the power of math as a social activity. How, rather than competing with my classmates, I could work with them to understand and discover new things. Mathematics took shape as a massively intricate monument to human creative activity. I had found my place.

Since then, both my confidence and my power as a mathematician have grown. My work has been honored occasionally, for example in an invitation to speak at the ICM, and in being awarded the Satter Prize. With age has come freedom to speak my mind, to act stupid, and to take risks. While research is as interesting as ever, my focus recently has also been on advising and mentoring, on helping to build the dynamics group at the University of Chicago, and on communicating mathematics to the world outside.

\section{Advice to Young Women}

To me, the joy in mathematics lies in the process of discovery, and the realm of dynamics presents an infinite zoo of possibilities to explore. When I was starting out, my goal was to figure out which way was up and how not to get lost. Over time this goal has evolved, and I am driven to discover new species and surprising behaviors in this zoo.

My advice is to try to be patient and enjoy the scenery.

\section{Photo Credit}

Photo of Amie Wilkinson courtesy of Amie Wilkinson. 


\section{Lauren Williams}

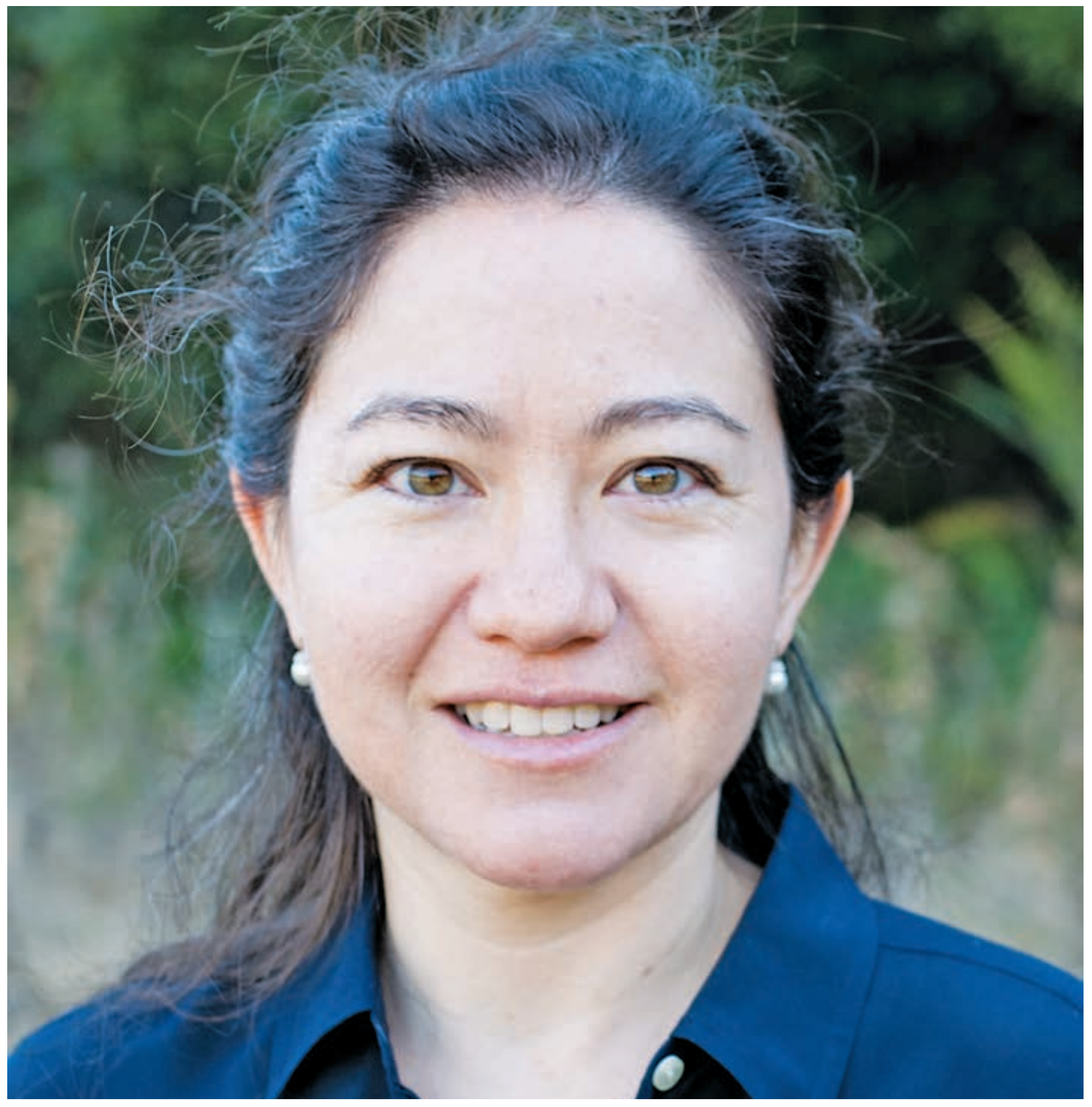




\section{WOMEN'S}

\section{HISTORY}

MONTH

\section{Synopsis of Research}

Lauren Williams is an algebraic combinatorialist, but she particularly enjoys working on problems that are at the interface between algebraic combinatorics and other fields. Some of her favorite research contributions include: a combinatorial formula for the stationary distribution of the asymmetric simple exclusion process (commonly cited as a model for traffic flow and translation in protein synthesis), joint with Sylvie Corteel; a polytopal manifestation of mirror symmetry for Grassmannians, joint with Konstanze Rietsch; a proof of Da Silva's conjecture on realizability of positively oriented matroids, joint with Federico Ardila and Felipe Rincon; the illumination of the role of the positive Grassmannian in the behavior of soliton solutions of the KP equation (used to model shallow water waves), joint with Yuji Kodama.

\section{Biography}

I grew up in a suburb of Los Angeles, the oldest of four girls. I liked math from an early age, but I also loved art, reading, writing poetry, and playing the violin. Once I started participating in math competitions and summer programs, I noticed that there were not very many girls involved; but the fact that my younger sisters were also good at math helped, I think, to mitigate any feelings of isolation. I majored in math at Harvard, spent a year at Cambridge doing Part III of the Mathematical Tripos, and then obtained my PhD from MIT under the supervision of Richard Stanley. After postdoctoral positions at UC Berkeley and Harvard, I joined the faculty at UC Berkeley in 2009, obtaining tenure in 2013. I have two kids, ages two and five, who bring me a lot of joy but also make the task of balancing my various responsibilities much harder! I have graduated six $\mathrm{PhD}$ students so far with five more current students. Some recent awards include the AWMMicrosoft Research Prize, the Rose Hills Innovator Award, a Simons Fellowship, an NSF CAREER Award, a Sloan Fellowship, the Prytanean Faculty Award (a mentoring award for Berkeley faculty), a Distinguished Undergraduate Teaching Award, and the 2018 Hardy Lectureship.

\section{Advice to Young Women}

My advice for young people, both women and men, is to find a subject area and problems that you care deeply about; I think it would be difficult to do good research (or find satisfaction in your work) otherwise. Additionally, mathematical research requires a great deal of patience, as there may be long periods of time when you don't make visible progress. In order to deal with this, I think it's quite important to have a deep reserve of self-confidence. I don't have any magic recipe for how to find this confidence, but I think it helps to surround yourself as much as possible with people who support you and to try not to compare yourself too much with others.

\section{Photo Credit}

Photo of Lauren Williams courtesy of Lauren Williams. 


\section{Melanie Matchett Wood}

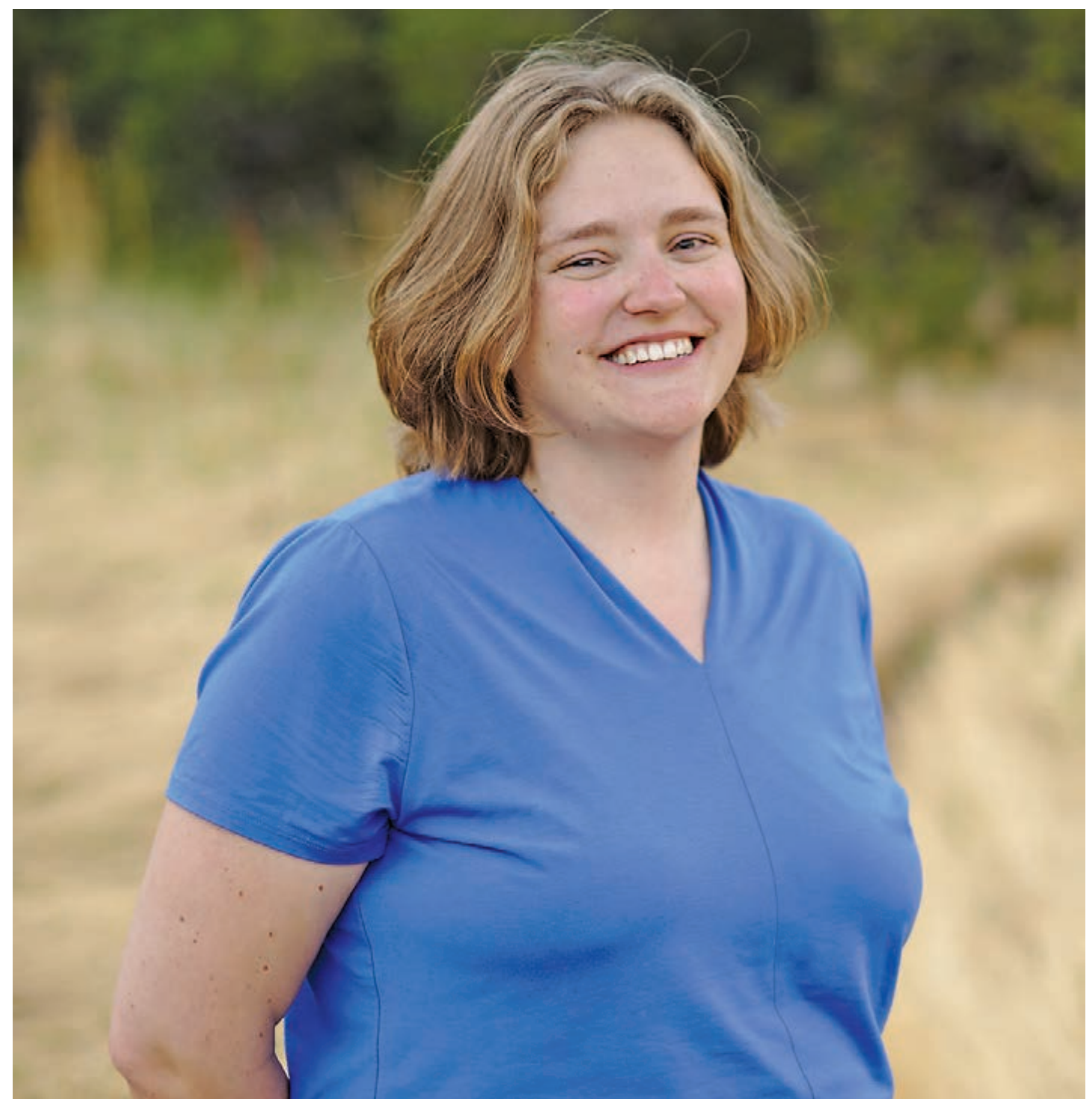




\section{WOMEN'S}

\section{HISTORY}

MONTH

\section{Synopsis of Research}

The main focus of Melanie Matchett Wood's research is in number theory and algebraic geometry, but it also involves work in probability, additive combinatorics, random groups, and algebraic topology. Much of Wood's work is motivated by questions of arithmetic statistics: How many are there of various number theoretic objects and what proportion of those objects have specified behaviors? An important example is to understand the distribution of class groups of random number fields. She has developed new conjectures on this topic for the non-Abelian analogs of class groups and proven theorems toward these conjectures in the function field case. Her future goals include further utilizing the insight that geometry gives in function field analogs to uncover new structure in the class groups of number fields.

\section{Biography}

In high school, I was the first female to represent the United States at the International Mathematics Olympiad. I went to college at Duke, where I was a Putnam Fellow and received the AMS-MAA-SIAM Morgan Prize. Then, I spent a year at the University of Cambridge doing Part III of their Mathematical Tripos. I received my PhD from Princeton in 2009, and then was a Szegő Assistant Professor at Stanford and an American Institute of Mathematics Five-Year Fellow. Now, I am a professor at the University of Wisconsin-Madison. Since 2011, I have been working part-time in my faculty position while I also stay at home with my young children. I am a Packard Fellow for Science and Engineering, a Sloan Research Fellow, and a National Science Foundation CAREER award winner. I am the 2018 recipient of the AWM-Microsoft Research Prize in Algebra and Number Theory. I was in the first class of the Fellows of the American Mathematical Society.

\section{Advice to Young Women}

My advice to young women is to decide what you want out of mathematics and to talk to others who have done what you would like to do to find out how to get there.

\section{Comments on Women's History Month}

It is important for all young people to have images and stories of people they can relate to doing the things that they might want to do when they grow up. When a group is underrepresented, such as women in mathematics, we need to make a special effort to make sure these stories reach young people so they can see what is possible.

\section{Photo Credit}

Photo of Melanie Matchett Wood courtesy of Joe Rabinoff. 